NBSIR 77-1404

\title{
Control of Mobile-Ion Contamination in Oxidation Ambients for MOS Device Processing
}

Santos Mayo, Richard Y. Koyama, and Thomas F. Leedy

Electronic Technology Division Institute for Applied Technology National Bureau of Standards Washington, D.C. 20234

January 1978

Final

Prepared for

Defense Nuclear Agency

Washington, D.C. 20305 



\section{CONTROL OF MOBILE-ION}

CONTAMINATION IN OXIDATION

\section{AMBIENTS FOR MOS DEVICE}

PROCESSING

Santos Mayo, Richard Y. Koyama, and Thomas F. Leedy

Electronic Technology Division Institute for Applied Technology National Bureau of Standards

Washington, D.C. 20234

January 1978

Final

\section{Prepared for}

Defense Nuclear Agency

Washington, D.C. 20305

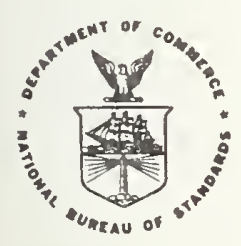

U.S. DEPARTMENT OF COMMERCE, Juanita M. Kreps, Secretary

Dr. Sidney Harman, Under Secretary

Jordan J. Baruch, Assistant Secretary for Science and Technology

NATIONAL BUREAU OF STANDARDS, Ernest Ambler, Acting Director 

TABLE OF CONTENTS

Page

Abstract . . . . . . . . . . . . . . . . . . 1

1. Introduction . . . . . . . . . . . . . . . . . . 1

2. The Experiment . . . . . . . . . . . . . . . . 3

3. Experimental Results . . . . . . . . . . . . . . 6

4. Discussion . . . . . . . . . . . . . . . . 9

Acknowledgment . . . . . . . . . . . . . . . . . 10

References . . . . . . . . . . . . . . . . . 10

Appendix 1 . . . . . . . . . . . . . . . . . 13

Appendix 2 . • . . . . . . . . . . . . . . . . . 19

Appendix 3 . . . . . . . . . . . . . . . . . . . 27

Distribution . . . . . . . . . . . . . . . . . 33

LIST OF FIGURES

Page

Figure 1. Double-wall transparent fused-silica tube used to grow silicon dioxide films ... . . . . . . . . 4

Figure 2. Mobile-ion density in oxide films grown in the double-wall oxidation tube with different atmospheres in the jacket . . . . . . . . . . . . 7 
Control of Mobile-Ion Contamination in Oxidation Ambients for MOS Processing

Santos Mayo, Richard Y. Koyama, and Thomas F. Leedy

Institute for Applied Technology

National Bureau of Standards

Washington, D. C. 20234

\section{Abstract}

An alternative method for controlling the mobile-ion contamination in the oxidation ambients for MOS device processing is explored. Mobile-ion contamination in silicon dioxide films thermally grown in dry oxygen at $1000^{\circ} \mathrm{C}$ on silicon substrates has been studied by use of a double-wall fusedsilica oxidation tube. The space between the tubes was alternatively filled with chlorine, room air, or sodium hydroxide gas to determine if a correlation exists between the presence of these substances in the jacket and the mobile-ion density in the oxide films. MOS capacitors were prepared on these films and mobile-ion densities were measured using conventional $\mathrm{C}-\mathrm{V}$ techniques. The ion densities ranged from $10^{13}$ to $10^{10} \mathrm{~cm}^{-2}$ as a function of the jacket atmosphere. These preliminary results suggest that there is a correlation between the presence of cleaning or contaminating agents in the jacket and the mobile-ion density in the oxide films. Both cleaning and contaminating actions occur through the tube wall.

Key words: Double-wa1l oxidation tube; dry oxidation; mobile-ion contamination; MOS device processing; MOS devices; oxidation ambient control; oxide growth; semiconductor device processing; silicon dioxide; thermal silicon dioxide films.

\section{Introduction}

Studies of the electrical properties of thin oxide films used in metal-oxide-semiconductor (MOS) structures have established that mobileion contamination in these oxide films causes instabilities of microelectronic devices. 1 Although the properties of the silicon dioxide film and its interfaces at the silicon and metal are not fully understood, ${ }^{2}$ and more systematic experimental observation is required, it is genera1ly agreed that alkali contamination of these films should be avoided in order to produce high quality MOS devices. ${ }^{3}$ Considerable efforts have been made to detect and neutralize, or eliminate, such contamination during process steps required for device fabrication. Extreme cleanliness during process operations has been recommended, and the use of u1trapure low mobile-ion chemicals has been explored. ${ }^{4}, 5$ The use of thin 
passivating layers of phosphosilicate glass or silicon nitride on silicon dioxide films has been reported, 6,7 and the addition of small quantities (a few mole percent) of chlorine or hydrogen chloride into the oxidation atmosphere $\mathrm{e}^{8-10}$ has been shown to facilitate the growth of high quality thermal silicon dioxide films.

The initial purpose of this task was to develop a measurement technique which could be used to determine directly the density of sodium in oxidation atmospheres used for the growth of thermal oxide films on silicon. Ideally, a technique for in situ measurement of trace contamination in furnace atmospheres would meet the following conditions: 1) the measuring system should be sensitive enough to detect impurity densities in the range of interest for semiconductor applications and 2) the equilibrium of the furnace atmosphere should be kept unperturbed during the measurements; for example, introduction of probes into the oxidation tube or the extraction of atmospheric samples should be avoided. In order to meet these requirements, a laser-induced resonance fluorescence technique was developed. This technique, which is sensitive to sodium in an atomic state only, was used to detect sodium in an open fusedsilica oxidation tube operated at $1000^{\circ} \mathrm{C}$. The minimum detectable sodium density was estimated to be approximately $5 \times 10^{5}$ atoms $/ \mathrm{cm}^{3}$. A copy of the paper which reported the details of this workll is included as Appendix 1. The results obtained through this technique led to the conclusion that atomic sodium is not the most abundant species in oxidation atmospheres contained in fused-silica tubes. Molecular sodium compounds appear to play an important role in the contamination of such atmospheres.

In view of the above conclusion, a thermodynamic study was made to evaluate the equilibrium sodium species in oxidation atmospheres contained in both fused silica and silicon tubes operated at $1000^{\circ} \mathrm{C}$. During thermal oxidation of silicon, impurities contained in the substrate or in the oxidation atmosphere come in contact with the growing oxide film and may become incorporated into it. Contamination of the oxidation ambient may result from impurities in the tube bulk incorporated during its fabrication process, $12-14$ and from contaminants which diffuse through the tube wall into the oxidation chamber.15 It was assumed that the source of sodium contamination in oxidation atmospheres was the tube wall. Commercially available transparent fused-silica tubes contain about $10 \mathrm{ppm}$ sodium ${ }^{12,13}$ while silicon tubes contain about $10 \mathrm{ppb}$ sodium. 14 Sodium in such tubes is assumed to be included as a solid solution of sodium metasilicate in the tube matrix $\left(\mathrm{Na}_{2} \mathrm{O} . \mathrm{SiO}_{2}(\mathrm{c})\right.$ in $\left.\mathrm{SiO}_{2}(\mathrm{c})\right)$. The thermodynamics of sodium vaporization from sodium silicate-silica glasses has been previously studied in the temperature range of 1200 to $2000 \mathrm{~K}$ where the equilibrium constant of the reaction $\mathrm{Na}_{2} \mathrm{O} . \mathrm{SiO}_{2}(\mathrm{c})$ in $\mathrm{SiO}_{2}(\mathrm{c}) \rightarrow 2 \mathrm{Na}(\mathrm{g})+\frac{1}{2} \mathrm{O}_{2}(\mathrm{~g})+\mathrm{SiO}_{2}(\mathrm{c})$ has been measured. 16 Using these results, reactions occurring at $1300 \mathrm{~K}$ on the tube wall were analyzed when oxygen, water, chlorine, or hydrogen are present in the tube atmosphere. Copies of the papers which report the results of these calculations 17,18 are included as Appendices 2 and 3. These calculations show that the presence of water in the oxidation ambient produces a rapid in- 
crease of the sodium number density from the $10^{7} \mathrm{~cm}^{-3}$ range corresponding to dry oxidation to about two orders of magnitude higher for water concentration of a few ppm. Also, the relevant reactions taking place during oxidation tube cleaning were thermodynamically analyzed. Empirically, it is known that the use of chlorine or hydrogen chloride for in situ cleaning of the oxidation tube in processing facilities is needed to grow oxide films with low mobile-ion content. Periodically, tubes are flushed for several hours with 5- to 10-percent hydrogen chloride diluted in an inert carrier gas. The calculations show that during cleaning the equilibrium sodium density increases by several orders of magnitude above the sodium level in the normal oxidation atmosphere. This cleaning produces a sodium-depleted layer at the tube wall adequate for growing clean oxide films.

Sodium diffuses easily in the tube bulk [diffusion coefficient in silicon dioxide: $\left.2 \times 10^{-6} \mathrm{~cm}^{2} / \mathrm{s}\right]^{19}$ to the tube wall surface and replenishes the layer depleted by cleaning, thus necessitating periodic cleaning. Contaminants from the furnace heating elements, the refractories, and the room air continually replenish and add to the sodium contamination in the tube wall. If the tube wall were essentially depleted of sodium and if external sources of sodium were eliminated for replenishing the tube wall, the oxidation ambient should contribute 1ittle mobileion contamination during MOS device processing. These arguments suggest the use of a double-wall oxidation tube containing chlorine gas between the inner and outer walls to provide a reactive sink and a barrier for alkali contamination.

This report summarizes preliminary data on this alternative method for the preparation of electrically stable thermal oxide films grown at $1000^{\circ} \mathrm{C}$ without specifically introducing any cleaning or passivating agents into the oxidation atmosphere.

\section{The Experiment}

Commercially available transparent fused-silica tubes of appropriate diameter were used to build a double-wall oxidation chamber with a 7$\mathrm{mm}$ wall separation as shown in figure 1 . This tube was operated at $1000^{\circ} \mathrm{C}$ in a three-zone resistance-heated furnace. At the tube ends, the inner and outer units were fused together to form a jacket around the oxidation chamber; no furnace liner was used. This configuration is similar to a single-wall oxidation tube using a fused-silica liner except for the joining at both ends. The tube was not cleaned prior to installation in the furnace. The oxidation tube temperature was constantly maintained at $1000 \pm 2{ }^{\circ} \mathrm{C}$. Except for short periods during in situ nitrogen anneal, the inner oxidation chamber was continuously filled with electronic grade dry oxygen flowing at a rate of $4 \mathrm{~cm}^{3} / \mathrm{s}$. Although this oxidation is nominally referred to as dry oxidation, it cannot strictly be considered so. The commercial electronic grade oxygen used contains about $5 \mathrm{ppm}$ water and $20 \mathrm{ppm}$ hydrocarbons measured as methane. 20 At oxidation temperature these hydrocarbons decompose producing additional water in the oxidation ambient. Moreover, it has been pointed out that 


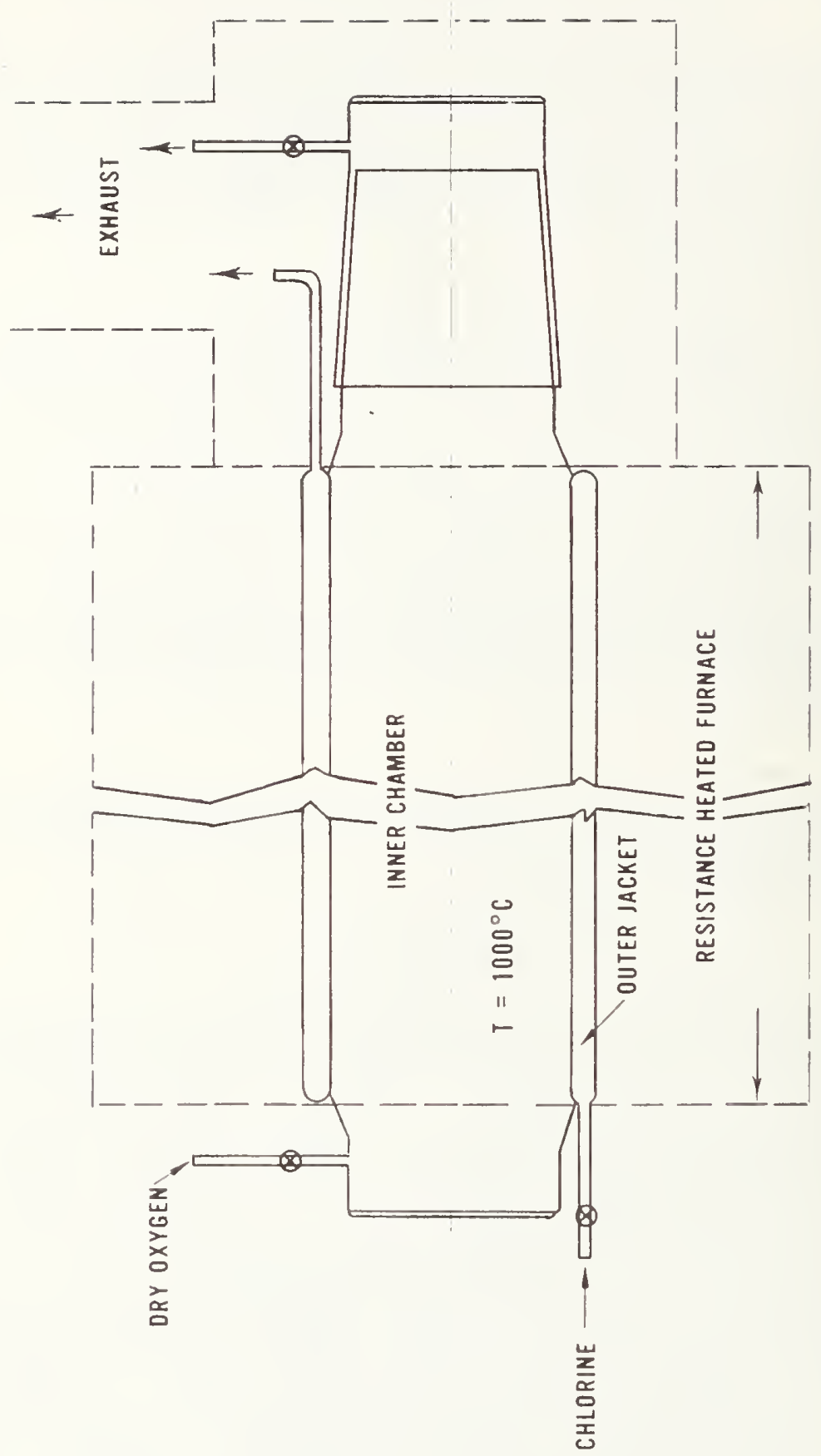

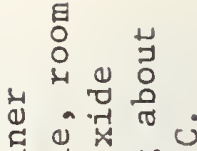

ב

त. 4 त 70

(1) 0 म न

더 어

0 य

i 40 H

तो ब ते

तु 400

4 वे

d)

- 4 यू U

से प्र

न 0 ग

द 1000

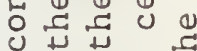

त म

r- 2 的

(1)

व

० ग

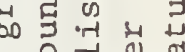

어 부요 है

$\exists+$ ज

व थ ज ए है

वैत ति

(1) नु

๑

$\Rightarrow$ क त

गु

त ब त्र ज म न त्र 10010 (1) 4 न न का ता ब

फै को का न्म

प 0 (1)

出星

击岕起

H D م

$\begin{array}{lllll}\pi & 5 & 0 & 0 & 4 \\ 0 & 0 & 0 & 0\end{array}$

क त ह 33

击出

प्र च 0 क

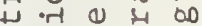

- $x$ व

न1 0 다

त

उ.

1)

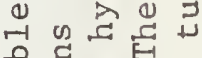

马

밍 W

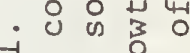

(4) मू 光是 क品 त.

ए गे 
at $1000^{\circ} \mathrm{C}$, water from the room air around the furnace can permeate through the $1-\mathrm{mm}$ thick fused-silica oxidation tube wall. Assuming 30 -percent relative humidity in the room air at $25^{\circ} \mathrm{C}$, the number of water molecules ${ }^{21}$ permeating through the tube wall is of the order of $10^{10} \mathrm{~cm}^{-2} \cdot \mathrm{s}^{-1}$. It has been shown that small amounts of water (ppm) in oxygen increase the silicon oxidation rate. 22-24 The chlorine barrier around the oxidation chamber constitutes a sink for water permeating through the tube wall, thus reducing the inclusion of water from room air humidity into the oxidation ambient. The jacket space between the inner and outer tubes was filled with either chlorine ( 99.9 percent), atmospheric room air, or dilute sodium hydroxide in nitrogen carrier gas, depending upon the desired condition while oxide films were grown in the excitation chamber. While chlorine was used, a porous quartz-wool plug was inserted into the exhaust port of the jacket to minimize chlorine loss to the furnace scavenger. This plug was removed during periods when room air was allowed to backstream into the jacket. The change in jacket atmosphere from air to chlorine could be made in a short interval, while the change from chlorine to air takes a much longer period until the residual chlorine in the jacket is exhausted. In the final stages of the experiment, external contamination was introduced into the jacket by passing nitrogen through a one-percent sodium hydroxide solution at room temperature; the gas was allowed to flow through the jacket by removing the plug from the exhaust.

MOS capacitors were used as test structures to determine the mobile ion content in 100-nm thick, thermal oxide films grown on 5-cm diameter (100) n-type silicon substrates with resistivity in the range from 5 to $10 \Omega \cdot \mathrm{cm}$. The silicon wafers (with one face polished, the other lapped and etched) were cleaned with conventional hydrogen peroxide-ammonia and hydrogen peroxide-acid solutions, rinsed in $18 \mathrm{M} \Omega \cdot \mathrm{cm}$ deionized water and spin-dried in nitrogen. 25 After dry oxidation at $1000^{\circ} \mathrm{C}$ for 212 min, the wafers were annealed in situ for $30 \mathrm{~min}$ in dry nitrogen.

Metallization by electron-gun evaporation of a $0.5-\mu \mathrm{m}$ aluminum layer on the oxide film immediately followed the annealing step. Photolithographic techniques were used to define the gate area.* The substrate contact was made by evaporation of a $0.2-\mu \mathrm{m}$ gold (with $0.6-$ percent antimony) layer on the entire back side. Finally, the capacitor was annealed at $500^{\circ} \mathrm{C}$ for $30 \mathrm{~min}$ in dry nitrogen. Processing steps such as wafer cleaning, oxidation, and metallization were accomplished in a systematic sequence with no delays or storage periods. To monitor accidental contamination introduced during steps other than oxidation, each lot of four processed wafers was divided into two groups of two wafers each. Two control wafers were oxidized in a conventional single-wall,

* The metallization pattern was taken from the fourth level of the NBS-3 mask set.26 Four capacitors of 381- $4 \mathrm{~m}$ diameter are available per cel1 and each cell is repeated across the wafer at 5.08-mm intervals. Three of the four capacitors have guard rings to control surface current if necessary. 
fused-silica oxidation tube provided with a liner; ${ }^{\dagger}$ the other two wafers were divided into halves along a diametertt and oxidized in the doublewall tube. With the exception of the oxidation step, the lot of four wafers was processed as a unit. The data on the control Mos capacitors were used to gauge the uniformity in the lot processing during the experiment.

The mobile-ion density of the thermal silicon dioxide films was determined from the flat band voltage shift of the Mos capacitors induced by bias-temperature-stress (BTS) testing using cycles of $\pm 10 \mathrm{~V}$ at $300^{\circ} \mathrm{C}$ for 5 min. The resulting electric field applied across the oxide film is about $10^{6} \mathrm{~V} / \mathrm{cm}$. The capacitance versus voltage $(\mathrm{C}-\mathrm{V})$ measurements were made at room temperature using a commercial capacitance bridge operating at $1 \mathrm{MHz}$ with an applied test signal of $15 \mathrm{mV}$. Although the entire wafer was temperature stressed for each BTS cycle, only specific capacitors (about 8 on each wafer) were bias stressed for a given BTS test. Assuming that the flat-band voltage shift is due entirely to the change in position of the mobile ions with respect to the silicon dioxidesilicon interface, the density of mobile ions, $Q_{0} / q$, is given in $\mathrm{cm}^{-2}$ by the expression: 27

$$
\frac{\mathrm{Q}_{\mathrm{O}}}{\mathrm{q}}=\Delta \mathrm{V}_{\mathrm{fb}} \frac{\mathrm{C}}{\mathrm{q}}=\Delta \mathrm{V}_{\mathrm{fb}} \frac{\varepsilon \varepsilon_{\mathrm{o}}}{\mathrm{qX} \mathrm{X}_{\mathrm{o}}}
$$

where $\Delta V_{f b}$ is the change in the flat-band voltage ( $V$ ) observed as a re-

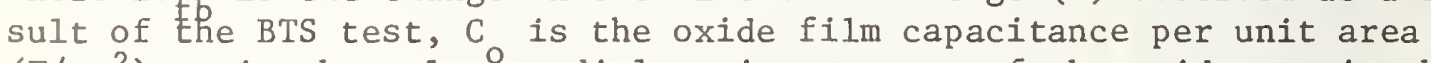
$\left(F / \mathrm{cm}^{2}\right), \varepsilon$ is the relative dielectric constant of the oxide, $\varepsilon$ is the permittivity of the free space $(F / c m), X_{0}$ is the oxide film thickness (cm), and $\mathrm{q}$ is the electronic charge.

\section{Experimental Results}

The results reported here were obtained during a time period of more than one year. Figure 2 shows the mobile-ion density in the Mos capacitors prepared in the double-wall tube. The dot on each bar is the average value of the span of data represented by the vertical bar. The variation of the mobile-ion density for a given data point represents the spread of the data taken over the complete lot of processed half wafers. This variation shows nonuniformity of the mobile-ion density with

The single-wall oxidation tube used a fused silica liner separated from the oxidation tube by quartz wool. The space between the liner and the oxidation tube was not sealed from the room air. The inner tube was periodically cleaned in situ for several hours with 5-percent hydrogen chloride diluted in dry nitrogen.

The diameter of the double-wall oxidation tube was such that only halfwafers (divided along a diameter) could be processed. 


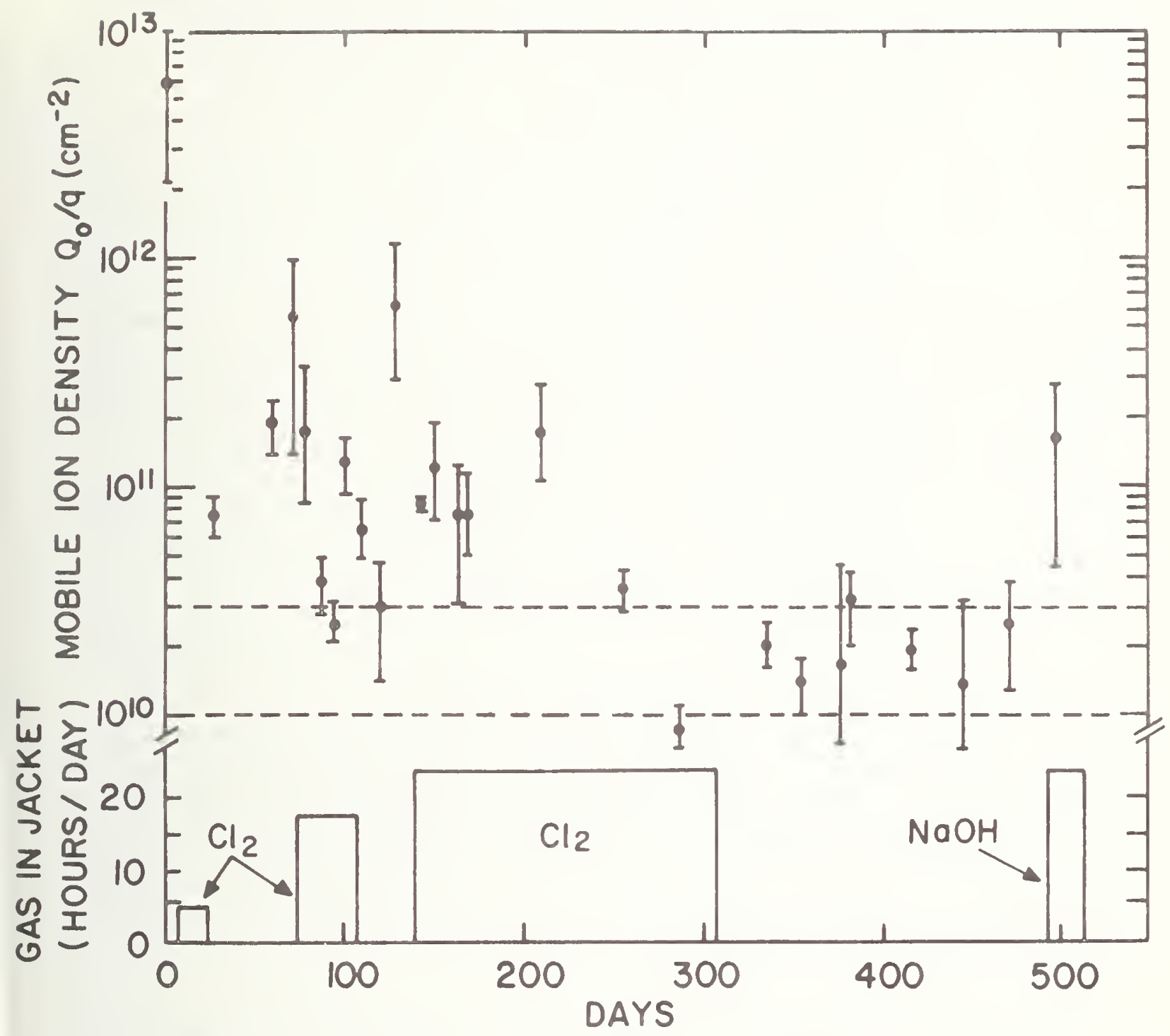

Figure 2. Mobile-ion density in oxide films grown in the double-wall oxidation tube with different atmospheres in the jacket. The dot on each bar is the average value of the span of data corresponding to a given wafer lot represented by the bars. The two dashed lines represent the range of mobile-ion density measured on the control wafers. The bottom part shows periods when chlorine, room air, or sodium hydroxide gas is allowed to fill the jacket. 
position on the wafer and does not reflect the measurement precision. (The technique is capable of resolving mobile-ion densities in the range of $4 \times 10^{9} \mathrm{~cm}^{-2}$ for $100-\mathrm{nm}$ thick oxides.) Such variation could possibly be interpreted in terms of localized clustering of the mobile ions. 28 The dashed lines represent the range of mobile-ion density of the control wafers with oxide films prepared in the single-wall oxidation tube. The bottom part shows the periods with chlorine, room air, and sodium hydroxide in the jacket. During the first, second, and third chlorine periods the gas was allowed to flow into the jacket for 5, 18, and 24 hours per day, respectively, while the quartz-wool plug was inserted into the exhaust port of the jacket. This allowed a gradual treatment of the tube with increasing chlorine concentration in the jacket.

After 200 days from the end of the last chlorine cleaning period, external contamination was introduced into the jacket. Nitrogen was passed through a one-percent sodium hydroxide solution at room temperature and the resulting gas was allowed to flow into the jacket for a period of $181 \mathrm{~h}$. Silicon dioxide films were grown during this period with sodium hydroxide in the jacket. The mobile-ion density in the oxide films was measured and an order-of-magnitude increase was observed (see fig. 2). This is due to sodium contamination in the oxidation atmosphere resulting from the passage of sodium through the tube wall.

The initial mobile-ion density in the $10^{12}$ to $10^{13} \mathrm{~cm}^{-2}$ range corresponds to MOS capacitors prepared on wafers which were processed prior to the first chlorine period; the double-wall tube initially had been installed in the furnace with no previous tube clean-up. The data show that the first two chlorine periods were not effective in achieving complete cleaning of the oxidation atmosphere. By the end of the third chlorine period the double-wall tube data are comparable to mobile-ion density data corresponding to control wafers processed in the singlewall oxidation tube. After the third chlorine period, contamination levels in oxides grown in both the double-wall and the single-wall oxidation tubes were similar. This result that was consistently observed for about 200 days is extremely encouraging considering that the tube was initially severely contaminated.

In order to investigate the possibility of chlorine from the jacket diffusing through the tube wall and becoming part of the oxidation ambient and thus passivating the mobile-ion content of the oxide, neutron activation analysis was used to obtain a measure of chlorine in the oxide films prepared in both the double-wall and the single-wall oxidation tubes. Samples of area about $1 \mathrm{~cm}^{2}$ were packaged in pure polyethylene bags and irradiated in the NBS reactor for periods of 10 and 20 min to thermal neutron fluences of 1.5 to $3 \times 10^{16} \mathrm{~cm}^{-2}$. These results indicate that the chlorine content in oxide films prepared in both the single-wall and the double-wall tubes during chlorine periods is about the same and equal to $10 \mathrm{ppb}$. Similar results obtained on plain unoxidized silicon substrates indicate higher chlorine content, presumably due to residual chlorine left on the wafers after the cleaning procedure. 25 
The results presented here suggest that the mobile-ion density in oxide films prepared in the double-wall fused-silica oxidation tube is influenced by the atmosphere established in the jacket. The first oxide film was grown immediately after the tube was installed in the furnace. The tube was not cleaned prior to installation and the jacket was open to the room air. The corresponding mobile-ion density resulted in the high $10^{12} \mathrm{~cm}^{-2}$ range. During the next 100 days, chlorine was used for two short periods separated by an interval with room air in the jacket. Oxide films grown during these 100 days show a one-order-of-magnitude reduction in the mobile-ion density. After the third chlorine period, room air was allowed into the jacket and several oxides were grown at various times during an interval of about 180 days. These oxides consistently exhibited mobile-ion densities within the range of control oxides prepared in the single-wall tube. This represents a reduction of two orders of magnitude in mobile-ion density with respect to the initial result. By using sodium hydroxide contamination in the jacket, the mobileion density was increased again by one order of magnitude. Both the cleaning action of chlorine and the contaminating action of the sodium hydroxide occur through the tube wall. A model describing the interactions in the tube with the jacket atmosphere would be valuable to interpret the present results. More theoretical and experimental work is required to understand the permeability of fused silica at $1000^{\circ} \mathrm{C}$ to various gases.

Neutron activation analysis results indicate that the chlorine content in oxides grown in the double-wall oxidation tube is only about 10 $\mathrm{ppb}$ (about $10^{14} \mathrm{~cm}^{-3}$ ). These results are consistent with results from ellipsometric determination of the index of refraction of these oxides at wavelength $632.8 \mathrm{~nm}$ where no significant departures from the nominal value $\mathrm{n}=1.462$ are observed. Changes in the index of refraction of $\Delta \mathrm{n}=$ 0.0018 to - 0.0079 have been reported in silicon dioxide films grown in oxygen with the addition of 0.5 to 2 volume percent chlorine at $1000^{\circ} \mathrm{C} .29$ Experimental evidence shows that thermal silicon dioxide films grown at $1100^{\circ} \mathrm{C}$ in one-percent hydrogen chloride in oxygen on (111) phosphorusdoped $10 \Omega \cdot \mathrm{cm}$ silicon wafers contain large amounts of chlorine. The residual chlorine profile measured by the Rutherford backscattering technique using a $2 \mathrm{MeV}-{ }^{4} \mathrm{He}$ beam indicates a chlorine content in these oxides higher than $10^{20} \mathrm{~cm}^{-3} .30$

Oxide films grown in the double-wall oxidation tube may also be of interest for fabricating radiation hardened devices. Although it has been established that there is little correlation between mobile-ion contamination in silicon dioxide films and radiation sensitivity of MOS devices, it has been recognized that the use of hydrogen chloride during oxidation to reduce the mobile-ion content in these films increases the device radiation sensitivity.31 Although the radiation sensitivity of the oxides produced in the double-wall tube has not been investigated, the technique provides an alternative to present radiation-hard oxide preparation methods requiring extensive hydrogen chloride tube cleaning 
periods prior to the oxide growth. ${ }^{31}$ The double-wall oxidation tube with the chlorine barrier requires no specific cleaning of the oxidation chamber. Hence, in principle, oxidation can occur on a continuous basis with no interruptions for routine clean-ups as required by the conventional hydrogen chloride oxidation chamber cleaning. However, additional experimental work is required to completely characterize these oxides.

\section{Acknowledgment}

The authors are grateful to R. M. Lindstrom and the Activation Analysis Section for measurements of chlorine content in silicon and thermal silicon dioxide films prepared for this work. Thanks are due to Drs. W. Murray Bullis and Kenneth F. Galloway for their constant stimulus for and criticism of this work.

\section{References}

1. Hickmott, T. W., Thermally Stimulated Conductivity of Sodium in Thermal $\mathrm{SiO}_{2}$, J. Appl. Phys. 46, 2583-2598 (1975).

2. Deal, B. E., The Current Understanding of Charges in the Thermally Oxidized Silicon Structure, J. Electrochem. Soc. 121, 198C-205C (1974) and Charge Effects and Other Properties of the $\mathrm{SiO}_{2}$-Si Interface: The Current Understanding, Semiconductor SiZicon 1977, H. R. Huff and E. Sirt1, Eds., pp. 276-296. Proceedings of the Third International Symposium on Silicon Materials Science and Technology, The Electrochemical Soc., Inc. (1977).

3. Derbenwick, G. F., Mobile Ions in $\mathrm{SiO}_{2}$ : Potassium, J. Appl. Phys. 48, 1127-1130 (1977).

4. Yurash, B., and Deal, B. E., A Method of Determining Sodium Content of Semiconductor Processing Materials, J. Electrochem. Soc. 115, 1191-1196 (1968).

5. Knolle, W. R., and Retajczyk, T. F., Jr., Monitoring Sodium Contamination in Silicon Devices and Processing Materials by Flame Emission Spectrometry, J. Electrochem. Soc. 120, 1106-1111 (1973).

6. Kerr, D. R., Logan, J. S., Burkhardt, P. J., and Pliskin, W. A., Stabilization of $\mathrm{SiO}_{2}$ Passivation Layers with $\mathrm{P}_{2} \mathrm{O}_{5}$, IBM J. Res. Develop. $8,376-384$ (1964).

7. Eldridge, J. M., Sodium Drift Through Phosphosilicate $\mathrm{Glass}^{-\mathrm{SiO}_{2}}$ Films, J. Electrochem. Soc. 118, 986-991 (1971), Balk, P., and E1dridge, J. M., Phosphosilicate Glass Stabilization of FET Devices, Proc. IEEE 57, 1558-1563 (1969).

8. Kriegler, R. J., Cheng, Y. C., and Colton, D. R., The Effect of HCl and $\mathrm{Cl}_{2}$ on the Thermal Oxidation of Silicon, J. Electrochem. Soc. $119,388-392$ (1972). 
9. Kriegler, R. J., Neutralization of $\mathrm{Na}^{+}$Ions in "HC1-Grown" $\mathrm{SiO}_{2}$, Appl. Phys. Lett. 20, 499-451 (1972).

10. Kriegler, R. Jo, The Role of HCl in the Passivation of MOS Structures, Thin Solid Films 13, 11-14 (1972).

11. Mayo, S., Keller, R. A., Travis, J. C., and Green, R. B., Detection of Sodium Trace Contamination in Furnace Atmospheres at $1000^{\circ} \mathrm{C}, \mathrm{J}$. Appl. Phys. 47, 4012-4106 (1976).

12. Hetherington, G., Stephenson, G. W., and Winterburn, J. A., Vitreous Silica in Electronics, Electronic Engineering 41, No. 495, 5256, and No. 496, 4447 (1969).

13. Owen, A. E., and Douglas, R. W., The Electrical Properties of Vitreous Silica, J. Soc. Glass Technology 43, 159T-178T (1969).

14. Dietze, W., Hunt, L. P., and Sawyer, D. H., The Preparation of CVDSilicon Tubes and Boats for Semiconductor Device Technology, J. Electrochem. Soc. 121, 1112-1115 (1974).

15. Fewer, D. R., and Gill, W. L., Investigation of Reliability Testing and Prediction Techniques for Integrated Circuits, Technical Report No. RADC-TR-66-345, pp. 33-46 (1966). Also available as NTIS Document $A D-489-969$.

16. Vidale, G. L., Measurement of the Absorption of Resonance Lines III, Vaporization of Sodium from Sodium Silicate Glasses, General Electric Co., Technical Information Series, R60SD390 (1960).

17. Mayo, S., and Evans, W. H., Development of Sodium Contamination in Semiconductor Oxidation Atmospheres at $1000^{\circ} \mathrm{C}$, J. Electrochem. Soc. $124,780-785$ (1977).

18. Mayo, S., and Evans, W. H., Thermodynamic Considerations in the Use of Polysilicon Oxidation Tubes for $\mathrm{Clean}^{\mathrm{SiO}} \mathrm{S}_{2} \mathrm{Film}$ Preparation, $J$. Electrochem. Soc. 125, 106-110 (1978).

19. Wolf, H. F., Silicon Semiconductor Data, pp. 526-527 (Pergamon Press, Oxford, 1969).

20. Matheson Gas Products, Oxygen Data Sheet.

21. Revesz, A. G., Noncrystalline Silicon Dioxide Film on Silicon: A Review, J. Noncmystalline Solids 11, 309-330 (1970).

22. Irene, E. A., The Effects of Trace Amounts of Water on the Thermal Oxidation of Silicon in Oxygen, J. Electrochem. Soc. 121, 16131616 (1974). 
23. Irene, E. A., and van der Meulen, Y. J., Silicon Oxidation Studies: Analysis of $\mathrm{SiO}_{2} \mathrm{~F} 1 \mathrm{~lm}$ Growth Data, J. Electrochem. Soc. 123, 13801384 (1976).

24. Irene, E. A., and Ghez, R., Silicon Oxidation Studies: The Role of $\mathrm{H}_{2} \mathrm{O}$, Semiconductor Silicon 1977, H. R. Huff and E. Sirtl, Eds., pp. 313-323 (The Electrochemical Society, Princeton, 1977).

25. Kern, W., and Puotinen, D. A., Cleaning Solutions Based on Hydrogen Peroxide for Use in Silicon Semiconductor Technology, RCA Review 31, 187-206 (1970).

26. Buehler, M. G., Microelectronic Test Pattern NBS-3 for Evaluating the Resistivity Dopant Density Relationship of Silicon, NBS Special Publication 400-22 (June 1976).

27. Grove, A. S., Physics of Semiconductor Devices, p. 339 (J. Wiley and Sons, Inc., New York, 1967).

28. DiStefano, T. H., Dielectric Breakdown Induced by Sodium in MOS Structures, J. App Z. Phys. 44, 527-528 (1973). Distefano, T. H., and Viggiano, J. M., Interface Imaging by Scanning Internal Photoemission, IBM J. Res. Develop. 18, 94-99 (1974).

29. van der Meulen, Y. J., Osburn, C. M., and Ziegler, J. F., Properties of $\mathrm{SiO}_{2}$ Grown in the Presence of $\mathrm{HCl}$ on $\mathrm{Cl}_{2}$, J. Electrochem. Soc. $122,284-290$ (1975).

30. Meek, R. L., Residual Chlorine in $\mathrm{O}_{2}$ : $\mathrm{HCl}$ Grown $\mathrm{SiO}_{2}$, J. Electrochem. Soc. 120, 308-310 (1973).

31. Gregory, B. L., Process Controls for Radiation-Hardened Aluminum Gate Bulk Silicon CMOS, IEEE Trans. Nucl. Sci. NS-22, 2295-2302 (1975). 


\title{
Detection of sodium trace contamination in furnace atmospheres at $1000^{\circ} \mathrm{C}^{*}$
}

\author{
Santos Mayo \\ Electronic Technalogy Division, Institure for Applied Technalogy. National Bureau af Standards, \\ Washington, D.C. 20234
}

Richard A. Keller

Physical Chemistry Divisian, Institute for Materials Research, Natianal Bureau of Standords, Washington, D.C. 20234

John C. Travis and Robert B. Green

\author{
Analytical Chemistry Division, Instituse far Moterials Research, Natianal Bureau af Standards, \\ Washingtan, D.C. 20234 \\ (Received 12 May 1976)
}

Free sodium atoms were detected by resonance fluorescence in an open contaminated quartz tube heated to $1000^{\circ} \mathrm{C}$. The quartz tube and furnace were similar to those used in semiconductor device processing. Fluorescence was excited by a $\mathrm{cw}$ dye laser tuned to the sodium $D_{1}$ or $D_{2}$ transition and directed along the axis of the furnace. Fluorescence from the sodium $D_{2}$ line emitted in the axial direction was collected by a telescopic system and focused onto a photomultiplier tube. The estimated minimum detectable sodium density in the furnace is $5 \times 10^{5}$ atoms $/ \mathrm{cm}^{3}$. No free sodium was detectable in a processing tube that had not been intentionally contaminated.

PACS numbers: $07.20 . \mathrm{Ka}, 32.10 . \mathrm{Hg}, 82.80 . \mathrm{Hn}$

\section{INTRODUCTION}

Sodium contamination in microelectronic devices has been correlated with erratic electrical behavior of these devices. ${ }^{1}$ The electrical properties of silicon dioxide films in metal-oxide-semiconductor (MOS) devices have been the subject of many investigations in which sodium was shown to be one of the principal causes of instabilities. ${ }^{2}$ Among other sources of sodium contamination such as those due to materials associated with the processing of semiconductor devices, ${ }^{3}$ the oxidation furnace atmosphere itself was suggested as a prominent one because of the high diffusion coefficient of sodium in silicon and silicon dioxide at temperatures used for oxidation. ${ }^{4}$ It has been postulated that sodium is transferred from the furnace material to the silicon wafer through the furnace atmosphere as free sodium atoms. Contamination control during device processing has been highly recommended to produce radiation hardened stable MOS devices. The mechanisms by which alkali contamination affects hardness are not well es tablished ${ }^{5}$ although ion microprobe studies of MOS devices show a correlation of sodium content in the oxide with radiation sensitivity. ${ }^{6}$ The purpose of this work is to develop a measurement technique for measuring sodium impurities in furnace atmospheres used in the growth of MOS oxides and in their subsequent annealing.

It is difficult to detect free sodium atoms at atmospheric concentration levels concomitant with the observed device contamination. Atomic absorption techniques are limited to concentration ranges above $10^{8}$ atoms $/ \mathrm{cm}^{3}$ by the difficulty of measuring small changes in transmitted light. ${ }^{7,8}$

Sodium concentrations as small as 100 atoms $/ \mathrm{cm}^{3}$ were recently detected in an evacuated tube at $-28^{\circ} \mathrm{C}$ by a resonance fluorescence technique. ${ }^{9-11}$ This paper reports on an extension of this method to an open quartz tube at $1000^{\circ} \mathrm{C}$. Problems associated with Doppler and collisional cross-section reduction, reaction of the sodium with oxygen and water, quenching of the emission by molecular collisions, and scattering from furnace gases, thermal gradients, suspended dust particles, and geometrical restrictions related to the structure of the furnace result in a poorer detection limit.

\section{EXPERIMENTAL METHOD}

A diagram of the apparatus used for the detection of resonance fluorescence from sodium vapor is shown in

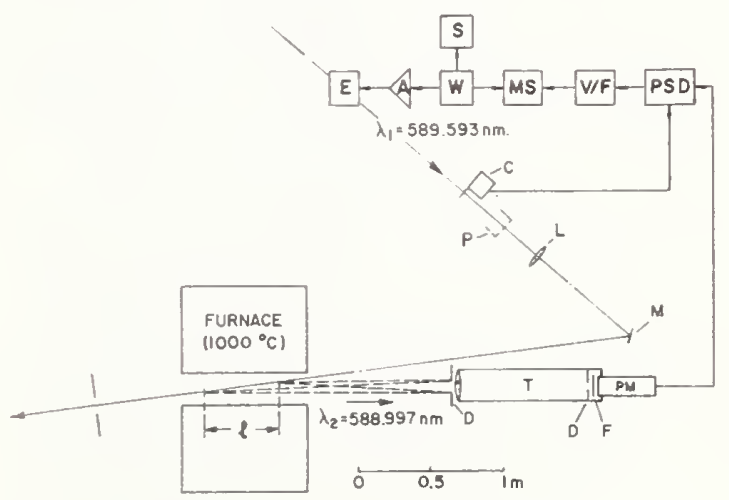

FIG. 1. Experimental arrangement for sodtum detection in a semiconductor processing furnace. E, 0.5-mm etalon mounted on torsion motor; $A$, power amplifier; $W$, sinusoidal wave generator $(0.5 \mathrm{~Hz}) ; \mathrm{S}$, sweep counter; MS, multiscaler; $\mathrm{V} / \mathrm{F}$, voltage to frequency converter; PSD, phase sensitive detector; $C$, chopper $(2 \mathrm{kHz}) ; \mathrm{P}$, power meter; $L$, lens; $M$, mirror; $T$, telescope; D, diaphragm; $F$, interference filter $11.25-\mathrm{nm}$ FWHM, 588.5 nm); PM, photomultipller tube; $l$, length of observation region. 


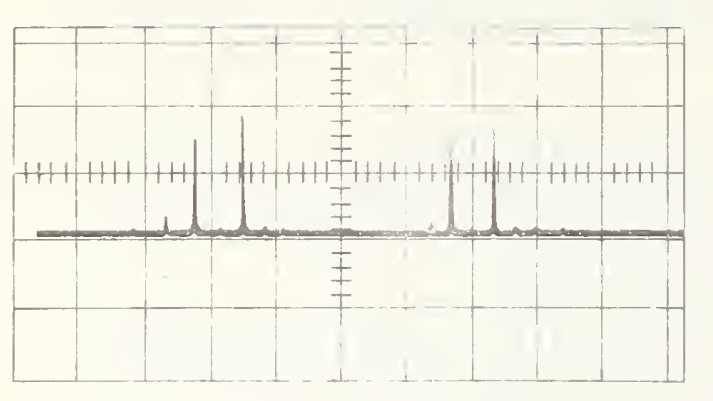

\section{$0.01 \mathrm{NM}$}

FIG. 2. Typical laser beam mode structure. The repetition of the pattern is due to the two spectral ranges covered by the spectrum analyzer.

Fig. 1. Amplitude-modulated radiation from a tunable dye laser passes down the furnace slightly off axis $\left(2^{\circ}\right)$ and through a hole in the laboratory wall. The fluorescence emission traveling out of the tube in the direction opposite to the laser bea $\mathrm{m}$ is collected by a telescopic system, passed through an interference filter (centered on the $D_{2}$ line), and focused onto a photomultiplier tube. The ac signal corresponding to the fluorescence is synchronously detected, digitized, and recorded on a multichannel analyzer as a function of the wavelengh of the excitation laser.

The excitation source was a commerical cw dye laser which was longitudinally pumped with powers up to $5 \mathrm{~W}$ by an all-line argon-ion $\mathrm{cw}$ laser. An intracavity birefringent filter was used to coarse tune the dye laser with a resultant bandwidth of $0.03 \mathrm{~nm}$. Insertion of a $0.5-\mathrm{mm}$ etalon into the cavity further narrowed the out put to $0.003 \mathrm{~nm}$. The mode structure of the dye laser was monitored by observing a small fraction of the beam with an interferometric spectrum analyzer (8-GHz free spectral range). A typical mode structure is shown in Fig. 2. These laser modes fall within the broadened absorption line of sodium $(\sim 0.01 \mathrm{~nm})$. The laser emission wavelength could be repetitively and reproducibly scanned over the absorption line by rotating the etalon through an angle of about $1^{\circ}$ with an oscillatory torsion motor driven by a low-frequency $(0.5 \mathrm{~Hz})$ low-amplitude sinusoidal wave. The laser was tuned to center the sodium $D_{1}$ resonance on the approximately linear portion of the sinusoidal wavelength scan. The signal-to-noise ratio was increased by repetitive scanning of the laser wavelength and summing the data from approximately 100 sweeps in the multichannel analyzer. The wavelength scale was calibrated by passing a portion of the output of the laser through the spectrum analyzer.

A major limitation to the minimum observable sodium signal was scattered laser light. Extreme care was necessary in the placement of optical components, apertures, and the dumping of the laser beam to minimize back reflection. Contributions from scattered light were further reduced by excitation of the $D_{1}$ line $(589.6 \mathrm{~nm})$ and observation of the $D_{2}$ emission $(589.0 \mathrm{~nm})$. At at- mospheric pressure, collisions with molecular nitrogen and oxygen in the furnace completely equilibrate the population of these two levels according to their statistical weights. ${ }^{12,13}$

The calibration necessary to relate the density of sodium atoms to the observed fluorescence signal was done by two methods. The first method involved a com parison of the fluorescence intensity from the sodium with the fluorescence intensity from a dilute solution of rhodamine $6 \mathrm{G}$ placed in a glass cell in the cooled furnace. The dimensions of the glass cell were the same as those of the quartz tube. The second method was based upon a calculation of the geometric factors involved in the detection optics and a measurement of the ratio of the intensity of the fluorescence emission to the excitation intensity. The methods yielded results that agreed within a factor of 3.

Sodium fluorescence signals were not observable in clean quartz tubes. Nonquantitative sodium contamination was intentionally introduced by aspirating dilute sodium chloride solutions into the hot tube for short periods of time and then waiting for several hours until a relatively constant level of contamination was observed.

\section{FLUORESCENCE SIGNAL RESULTS}

The fluorescence signal from sodium vapor inside of the quartz tube is shown in Fig. 3. These data are the accumulation of $1002-\mathrm{sec}$ sweeps. The average excitation power was $70 \mathrm{~mW}$. The observed linewidth of the excitation spectrum $(7.5 \mathrm{GHz}$ or $\sim 0.0 \mathrm{~nm})$ agrees well with the calculated linewidth taking into account Doppler $(2.7 \mathrm{GHz})$ and pressure $(6.2 \mathrm{GHz})$ broadenings under the conditions of the experiment. This good agreement is indicative of the frequency stability of the laser system. Background blackbody emission from the furnace was discriminated against by the sodium interference filter and synchronous detection. The nonzero signal observed off resonance is caused by scattered laser light. The scattered light signal is reduced approximately an order of magnitude when the $D_{1}$ tran-

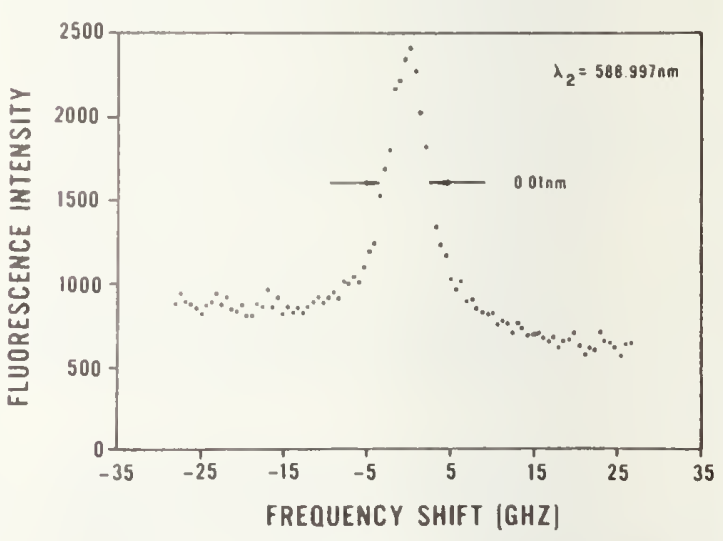

FIG. 3. Sadium fluorescence signal detected in contaminated furnace atmoshpere pressure, $1000^{\circ} \mathrm{C}$. This signal corresponds to $2.5 \times 10^{7}$ sodium atoms $/ \mathrm{cm}^{3}$. 
TABLE I. Constants for calibratiou using thodamu GC,

\begin{tabular}{llll}
\hline \hline$I_{\mathrm{R}}(589.0) / I_{\mathrm{Na}}(589.0)$ & $\left(1.19^{\mathrm{a}}\right.$ & $I_{0}(589.6)$ & $70 \mathrm{~mW}$ \\
$\sigma_{\mathrm{R}}(571.8)$ & $2.4 \times 10^{-18} \mathrm{~cm}^{2 \mathrm{a}}$ & $Q_{\mathrm{R}}$ & $0.85(\mathrm{Ref} .14)$ \\
$\sigma_{\mathrm{Na}}(589.6)$ & $7.8 \times 10^{-13} \mathrm{~cm}^{2 \mathrm{~b}}$ & $Q_{\mathrm{Na}}$ & $0.01-0.04(\mathrm{Refs}, 15 \mathrm{and} 16)$ \\
$N_{\mathrm{R}}$ & $3.5 \times 10^{13} / \mathrm{cm}^{3 \mathrm{a}}$ & $A_{\mathrm{R}}$ & $6.1 \times 10^{-3 \mathrm{~b}}$ \\
$I_{0}(571.8)$ & $9.0 \mathrm{~mW}$ & $A_{\mathrm{Na}}$ & $0.31 \mathrm{~b}$ \\
\hline
\end{tabular}

axperimentally determined.

${ }^{\mathrm{C}}$ Calculated.

sition is excited and the emission observed, in agreement with the transmission characteristics of the interference filter. Any reduction in the absolute magnitude of the scattered light results in a reduction in the associated shot noise and in noise resulting from fluctuations in the scattering medium. After careful alignment of the optical system, a major contribution to the scattered light was reflections from suspended dust particles in the tube. This contribution could be reduced by flushing the tube with clean nitrogen. A statistical analysis of the data in Fig. 3 shows that the ratio of the fluorescence signal at the peak to the noise in the scattered light is $>50$. The long-term precision is better than $10 \%$.

\section{CALIBRATION 1}

The quartz tube was replaced by a room-temperature cell containing a dilute solution of rhodamine 6G dis solved in ethyl alcohol. Absorption cross sections and fluorescence quantum yields for this material are well known. ${ }^{14}$ For the measurement of the fluorescence intensity at the wavelength of the sodium $D_{2}$ line, it was expedient to irradiate at a shorter wavelength to provide a reasonable cross section and to reduce scattered light from the windows of the cell and dust particles in the liquid. A convenient wavelength was found to be around $570 \mathrm{~nm}$. The laser beam was deflected by the solution and windows on the cell, requiring a slight realignment of the optics to maximize the fluorescence signal and minimize the scattered light.

The calibration process can be understood by considering the following equations:

$$
\begin{aligned}
& I_{\mathrm{R}}(589.0)=\sigma_{\mathrm{R}}(571.8) N_{\mathrm{R}} l I_{0}(571.8) Q_{\mathrm{R}} A_{\mathrm{R}} G, \\
& I_{\mathrm{Na}}(589.0)=\sigma_{\mathrm{Na}}(589.6) N_{\mathrm{Na}} l I_{0}(589.6) Q_{\mathrm{Na}} A_{\mathrm{Na}_{\mathrm{a}}} G .
\end{aligned}
$$

$I_{\mathrm{R}}$ and $I_{\mathrm{Na}}$ are the measured fluorescence intensities from rhodamine and sodium, the o's are the absorption cross sections at the indicated wavelengths, the $N$ 's are atomic or molecular densities, $l$ is the length from which fluorescence is being detected, the Q's are fluorescence quantum yields, the $A$ 's are the spectral fraction of the emitted light passed by the interference filter, and $G$ is a geometric collection factor assumed similar for both samples. Taking the ratio of Eq. (1) and Eq. (2) and solving for $N_{N a}$ gives Eq. (3),

$N_{\mathrm{Na}}=N_{\mathrm{R}} \frac{I_{\mathrm{Na}}(589.0)}{I_{\mathrm{R}}(589.0)} \frac{\sigma_{\mathrm{R}}(571.8)}{\sigma_{\mathrm{Na}_{\mathrm{a}}}(589.6)} \frac{I_{0}(571.8)}{I_{0}(589.6)} \frac{Q_{\mathrm{R}}}{Q_{\mathrm{Na}}} \frac{A_{\mathrm{R}}}{A_{\mathrm{Na}}}$

All quantities in Eq. (3) are known or can be measured. $A_{\mathrm{R}}$ is found by folding the transmission curve of the interference filter $\{T(\lambda)\}$ into the spectral emission curve of the dye $[F(\lambda)]$.

$$
A_{\mathrm{R}}=\int T(\lambda) F(\lambda) d \lambda / \int F(\lambda) d \lambda .
$$

$A_{\mathrm{N}_{\mathrm{a}}}$ is calculated by assuming equal population among the substates of $D_{1}$ and $D_{2}$ levels and including the effects of the interference filter,

$$
A_{\mathrm{Na}}=\frac{2}{(4+2)} T(589.6)+\frac{4}{(4+2)} T(589.0) .
$$

The statistical weights of the $D_{1}$ and $D_{2}$ levels are 2 and 4 respectively. $\sigma_{N a}$ can be calculated from the oscillator strength and the calculated linewidth contributions. ${ }^{13}$ The quantities for $\mathrm{Eq}$. (3) are given in Table $1,{ }^{15,16}$

\section{CALIBRATION 2}

Equation (2) relates the observed fluorescence intensity to the density of sodium atoms. Rearrangement of this equation for the case where both excitation and observation are at $589.0 \mathrm{~nm}$ gives

$$
N_{\mathrm{Na}}=\frac{I_{\mathrm{N}_{2}}(589.0)}{I_{0}(589.0)}\left[\sigma_{\mathrm{Na}}(589.0) l Q_{\mathrm{Na}} A_{\mathrm{Na}} G\right]^{-1} \text {. }
$$

All quantities to the right of the equality sign are known or can be measured. The values of $\sigma, l, Q$, and $A$ are listed in Tables I and II. The intensities of the sodium fluorescence and laser excitation were measured by comparison with an electrically calibrated pyroelectric detector. ${ }^{17}$ Neutral-density filters were used with PIN diodes to change intensities in known ratio, into the range of linearity for these devices. The geometric collection factor was evaluated by consideration of the optical design shown in Fig. 1.

The results of both calibrations are listed in Table III. The data for calibration 2 were preliminary and are recorded here only as an independent check on later results.

\section{OXIDE IMPURITY RESULTS}

A clean (the quartz tube was rinsed in hydrofluoric and nitric acid solutions and washed in deionized water)

TABLE II. Additional constants for calibration with calculated geometric factors.

\begin{tabular}{llll}
\hline$\sigma_{\mathrm{Na}}(589.0)$ & $1.5 \times 10^{-12} \mathrm{~cm}^{2 \mathrm{a}}$ & $G$ & $5.5 \times 10^{-4}$ \\
$I_{\mathrm{Na}}(589.0)$ & $360 \mathrm{pW}^{\mathrm{b}}$ & $l$ & $60 \mathrm{~cm}^{\mathrm{b}}$ \\
$I_{0}(589.0)$ & $140 \mathrm{~mW}$ & & \\
\hline \hline
\end{tabular}

a Calculated.

${ }^{b}$ Experimentally determined. 
TABLE III. Observed sodium densities and estimated minimum detectable quantities. a

\begin{tabular}{|c|c|c|c|}
\hline Calibration & $\begin{array}{l}\text { Na density } \\
\left(\text { atoms } / \mathrm{cm}^{3} \text { ) }\right.\end{array}$ & $S / N$ & $\begin{array}{l}\text { Minimum detectable } \\
\text { quantity b (atoms } / \mathrm{cm}^{3} \text { ) }\end{array}$ \\
\hline 1 (rhodamine) & $3-12 \times 10^{7}$ & 56 & $5-20 \times 10^{5}$ \\
\hline 2 (geometric) & $4-16 \times 10^{6}$ & 22 & $2-8 \times 10^{5}$ \\
\hline
\end{tabular}

${ }^{\mathrm{a}}$ Range reflects uncertainty in $Q_{\mathrm{Na}}$.

bignal to noise equal to two.

quartz furnace tube with end caps was used to grow oxide films on silicon wafers. After the oxide film was prepared, the end caps were removed (water from ambient humidity may have diffused into the tube during the measurement; see Sec. VII) and it was found that no sodium fluorescence was observable within the detection limits reported in Table III. The oxide films grown on silicon in this clean tube showed an order of magnitude higher sodium contamination level than is normally present on similar films prepared in produc tion-type semiconductor processing oxidation tubes operated in a controlled environment. These results were obtained by capacitance-vs-voltage measurements performed on MOS capacitors after application of simultaneous electric bias and temperature stress cycles. Electric fields of about $10^{6} \mathrm{~V} / \mathrm{cm}$ were established a cross the oxide film by use of positive or negative $10-\mathrm{V}$ gate polarization while the device temperature is maintained at $300^{\circ} \mathrm{C}$ for $10 \mathrm{~m}$ in (MOS-CV-BT stress technique). ${ }^{18}$

Similar oxide layers were grown on silicon in a sodium-contaminated oxidation tube where sodium fluorescence from approximately $10^{7}$ atoms $/ \mathrm{cm}^{3}$ was measureable. MOS capacitors built on this oxide exhibited two orders of magnitude more sodium content than similar control capacitors prepared in a standard processing facility as measured by the MOS-CV-BT stress technique.

\section{DISCUSSION}

It is important to note that the technique described above is a measurement of free sodium atoms only. Sodium present in compounds (e. g. , $\mathrm{Na}_{2} \mathrm{O}$ and $\mathrm{NaOH}$ ) would not be detected. These results are important for understanding the apparent discrepancy between the oxide impurity measurements and the resonance fluorescence results. It is a difficult thermodynamic problem to estimate the concentration of oxides and the hydroxide from a knowledge of the free sodium concentration because the concentrations of other species (e.g. , $\mathrm{H}_{2}$ and $\mathrm{OH}$ ) are uncertain by many orders of magnitude. It should be possible to measure the hydroxyl radical concentration in the furnace by a similar resonance fluorescence technique. ${ }^{19}$ Knowledge of both the free sodium and the hydroxyl radical concentration could be used to determine the sodiuns hydroxide concentration.

In a production semiconductor processing furnace, where the oxidation atmosphere is completely enclosed in the quartz tube and carefully controlled dry oxygen is used, a more favorable ratio of free sodium to total sodium might be expected. Such conditions would inprove the atomic measurement except for additional sources of light scattering at the capped tube ends. However, these sources of interference could be practically eliminated by an alternative geometry discussed below.

There are several improvements which should decrease the detection limits reported above. The first of these involves frequency modulation of the excitation beam and synchronous detection of the fluorescence to reduce contributions from frequency-independent scat tering. Frequency modulation of the $\mathrm{cw}$ dye laser is relatively straightforward.

Scattered light could be significantly reduced by using a monochromator in place of the interference filter to completely isolate the $D_{1}$ excitation from the $D_{2}$ emission. The insertion of the monochromator may reduce the total number of photons reaching the photomultiplier tube to the extent that photon counting might be necessary.

A reduction of scattered light and an increase in light gathering power could be accomplished by mounting the detecting optics in ports distributed down the tube and viewing the fluorescence at right angles to the excitation. This has two additional advantages: (1) information on the spatial distribution of the contamination would now be available by viewing through different ports: (2) windows on the quartz tube would not interfere with the neasurement because laser scattering from them would be far from the field of view subtended by the detector.

\section{ACKNOWLEDGMENTS}

The completion of this project was facilitated by nany fruitful discussions with Gabriel Luther of the Quantum Metrology Section. Thanks are also due to John Geist and Edward Zalewski of the Radiometric Physics Section for help in the absolute measurement of light intensities.

- Thls meseaich was conducted under the jolnt ausplces of the Semiconductor Technology Program and the Laser Chemistry Program of the Natlonal Bureau of Standards. Partlal support was providcd by the Dcfense Nuclear Agency.

'R. J. Krlegler, $12 t h$ Anmal Proceedings Reliability Physics 1974 (IEEE, New York, 1974), p. 250.

${ }^{2}$ T.W. Hickmott, J. Appl. Phys. 46, 2583 (1975)

${ }^{3}$ B. Yurash and B. E. Deal, J. Electrochem. Soc. 115, 1191 (1968).

${ }^{4}$ D. R. Fewer and W. L. Gell, Texas Instruments Inc., Technical Report No. RADC-TR-66-345, 1966 (unpubllshed).

${ }^{5}$ B. L. Gregory, IEEE Trans. Nucl. Sc1. NS-22, 2295 (1975).

${ }^{6}$ 11. Hughes, R. D. Baxter, and B. Phlllips, IEEE Trans.

Nucl. Sci. NS-19, 256 (1972).

${ }^{7}$ T. E. Burgess and H. M. Donega, J. Electrochem. Soc. 116, 1313 (1969).

${ }^{6}$ N. Ioll, F. Strumia, and A. Moretti, J. Opt. Soc. Am. 61, 1251 (1971). 
${ }^{9}$ D. A. Jennings and R. A. Keller, J. An. Chen. Soc. 44, 9249 (1972).

${ }^{10}$ W.M. Fal rbank, Jr., T. W. Hänsch, and A. L. Schawlow, J. Opt. Soc. Am. 65, 199 (1975)

${ }^{11}$ F. C. M. Coolen and H. L. Hagedoorn, J. Opt. Soc. Am. 65, 952 (1975).

${ }^{12}$ M. Stupavsky and L, Krause, Can, J, Phys, 46, 2127 (1968)

${ }^{13}$ A. C. G. Mitchell and M.W. Zemansky, Resonance Radiation and Excited Atoms (Cambridge U. P., Cambrldge, England, 1971), p. 100 .

14J. P. Webb, W.C. McColgin, O.G. Peterson, D. L. Stockman, and J.H. Eberly, J. Chem. Phys, 53, 4227 (1970).
${ }^{15}$ D. R. Jenkins, Proc. R. Soc. Iondon A 293, 493 (1966)

${ }^{16}$ H. P. Hooymaycrs and C. Th. J. Alkemade, J. Quant. Spectrosc. Radlat. Transfer 6, 847 (1966).

${ }^{17} \mathrm{~J}$. Gelst, B. Steiner, R. Schaefer, E. Zalewski, and A Corrons, Appl. Phys. Lett. 26, 309 (1975)

${ }^{18}$ R. Y. Koyama and M. G. Buehler, Semiconductor Measurement Technology, edited by W.M. Bullis, NBS Spectal Publication No. 400-4 (U.S. GPO, Washington, D.C., 1974), pp. 37-39.

${ }^{19}$ C. C. Wang and L. I. Davis, Jr. , Phys. Rev. Lett. 32, 349 (1974). 


\title{
Development of Sodium Contamination in Semiconductor Oxidation Atmospheres at $1000^{\circ} \mathrm{C}$
}

\author{
Santos Mayo \\ Electronic Technology Division, Institute for Applied Technology. \\ National Bureau of Standards, Washington, D.C. 20234 \\ and William H. Evans \\ National Bureau of Standards, Physical Chemistry Division, \\ Institute for Materials Research, Washington, D.C. 20234 \\ Reprinted from Journal of the Electrochemical Society \\ Vo1. 124, No. 5, May 1977 \\ Printed in the U.S.A.
}




\title{
Development of Sodium Contamination in Semiconductor Oxidation Atmospheres at $1000^{\circ} \mathrm{C}$
}

\author{
Santos Mayo \\ Electronic Technology Division, Institute for Applied Technology, \\ National Bureau of Standards, Washington, D.C. 20234 \\ and William H. Evans \\ National Bureau of Standards, Physical Chemistry Division, \\ Institute for Materials Research, Washington, D.C. 20234
}

\begin{abstract}
The thermodynamic equilibria established in fused silica oxidation tubes operated at $1000^{\circ} \mathrm{C}$ are analyzed. Transparent fused silica tubes used for thermal oxidation of silicon contain about $10 \mathrm{ppm}$ sodium impurity. At oxidation temperatures sodium diffuses in fused silica, evaporates into the oxidation ambient, and reacts with residual water contaminating the oxidation atmosphere. During the oxidation cycle enough sodium is incorporated into the growing oxide film to be detected later by capacitance measurements in metal oxide semiconductor (MOS) structures. Reactions taking place during currently used in situ furnace cleaning procedures are analyzed. Calculations indicate that the amount of sodium removed from the fused silica tube wall through chlorine or hydrogen chloride cleaning is substantial. The reaction rate is regulated by diffusion of sodium in the fused silica. The use of iodine and hydrogen iodide as cleaning agents is discussed.
\end{abstract}

Oxidation of silicon has been the subject of many investigations aimed at understanding metal oxide semiconductor (MOS) device instabilities caused by the action of mobile ion impurities localized in the oxide film (1). Test vehicles in the form of simple MOS capacitors built on silicon dioxide flms 50-100 $\mathrm{nm}$ thick are frequently used to study ionic contamination in thermal silicon dioxide. The mobile ion density in the oxide film can be calculated from capacitance measurements after thermal cycles have been applied to the device (2).

Several contamination sources may contribute impurities to the oxide film. Due to their high natural abundance, alkali species are the most common impurities likely to contaminate silicon dioxide. Sodium, potassium, and lithium may cause ionic-type instabilities in the oxide. Sources of alkali contamination can be classifled according to their origin as: (i) bulk and surface impurities already contained in the silicon wafer before oxidation, (ii) impurities introduced into the oxide fllm during silicon high temperature oxidation and annealing, and (iii) impurities introduced after oxidation through metallization (3).

Considerable research has been done to determine the presence of impurities in microelectronic process materials. Analytical techniques such as flame emission, atomic absorption, resonance fluorescence, neutron activation, and others have been used for trace contamination detection (4-6). Metallization of microelectronic devices has also received a great deal of attention regarding the introduction of ionic contamination in the oxide film from both the evaporation process used and contamination in the metal (7). These results show that impurities may be introduced through several processing steps and play a significant role in determining the electrical properties of the device.

During oxidation of silicon, sodium impurity contained in fused silica oxidation tubes evaporates from the tube wall into the oxidation ambient. In typical oxidation facilities, furnaces employing fused silica tubes are operated at about $1000^{\circ} \mathrm{C}$ (or $1300^{\circ} \mathrm{K}$ for

Key words: fused slllca, oxldation furnace, semlconductor proo essing, sillcon dloxide, thermal oxidation. the purpose of this paper). The oxidation atmosphere generally consists of pure dry oxygen flowing along the tube with laminar flow at about $4 \mathrm{~cm}^{3} / \mathrm{sec}$ (equivalent-to 0.5 std $\mathrm{ft}^{3} / \mathrm{hr}$ ). Transparent commercial fused silica tubes currently used for this purpose generally have an average sodium content of $10 \mathrm{ppm}(8-9)$. Sodium in the tube bulk diffuses easily [diffusion coefficient in $\left.\mathrm{SiO}_{2}: 2 \times 10^{-6} \mathrm{~cm}^{2} / \mathrm{sec}(10)\right]$ to the tube wall surface. This in turn causes the appearance of contamination in silicon dioxide films grown in the oxidation tube (11).

The purpose of this work is to study the oxidation atmosphere used to grow thermal silicon dioxide films as a source of sodium contamination introduced into the film during the growing cycle. The thermodynamic equilibria established in fused silica oxidation tube atmospheres at $1300^{\circ} \mathrm{K}$ were considered.

\section{Reactions Occurring in Fused Silica Oxidation Tubes}

The thermodynamics of sodium vaporization from sodium silicate-silica glasses has been previously studled in the temperature range of $1200^{\circ}-20.0^{\circ} \mathrm{K}$ where the equilibrium constant of the reaction $\mathrm{Na}_{2} \mathrm{O} \cdot \mathrm{SiO}_{2}$ $\left(\right.$ in $\mathrm{SiO}_{2}$ ) $\rightarrow 2 \mathrm{Na}(\mathrm{g})+1 / 2 \mathrm{O}_{2}(\mathrm{~g})+\mathrm{SiO}_{2}$ (c or glass) has been measured (12). Values of $K=p^{2}(\mathrm{Na})$. $p^{\prime / o}\left(\mathrm{O}_{2}\right)\left[a\left(\mathrm{SiO}_{2}\right) / a\left(\mathrm{Na}_{2} \mathrm{O} \cdot \mathrm{SiO}_{2}\right)\right]$ were reported for molar ratios of $\mathrm{SiO}_{2}$ to $\mathrm{Na}_{2} \mathrm{O}$ varying from $1.69: 1$ to 3.88:1, where the a's (activities) were expressed in terms of mole fractions. The results indicated Raoult law behavior was approximated in the higher ratio solutions. On this basis, extrapolation to larger ratios, i.e., $10^{5}$ (about $10 \mathrm{ppm}$ sodium in the silica) leads to the value $\mathrm{K}=2.5 \times 10^{-19}$ at $T=1300^{\circ} \mathrm{K}$. Using this value and thermodynamic data from Table VII we obtain $\mathrm{AH}^{\circ}{ }_{1293}\left(\mathrm{Na}_{2} \mathrm{O} \cdot \mathrm{SiO}_{2} \mathrm{~L}_{10}{ }^{5}\right.$ mole fraction in $\left.\left.\mathrm{SiO}_{2} \mathrm{gls}\right]\right)=-376.8 \mathrm{kcal} / \mathrm{mole}$. This value is in reasonably good agreement with the corresponding JANAF (13) value for $\mathrm{Na}_{2} \mathrm{O} \cdot \mathrm{SiO}_{2}$ (gls) of $373.2 \mathrm{kcal} / \mathrm{mole}$. The difference between these values can be considered a measure of the solution effects, such as formation of $\mathrm{Na}_{2} \mathrm{O} \cdot x$ SiO, species, and the difference between the properties of the simple compound as a glass and the same species in solution. For this reason the use 
Table 1. Equilibrium atmosphere in fused silico dry oxidation rube ot $1300^{\circ} \mathrm{K}$. Sodium content in fused silico bulk is $10 \mathrm{ppm}$, oxygen of $1 \mathrm{otm}$.

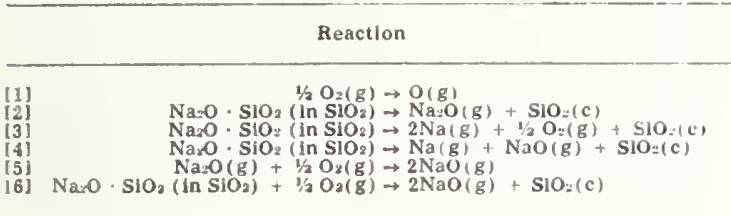

of the former value $(-376.8 \mathrm{kcal} / \mathrm{mole})$ derived from measurements (12) was preferred, assuming that any systematic errors in the calculations would be partially compensated.

A number of reactions take place in fused silica oxidation tubes operated at $1300^{\circ} \mathrm{K}$. Table 1 shows the equilibrium ${ }^{1}$ atmosphere resulting from 1 atm dry oxygen reacting with the tube wall. The partial pressure corresponding to atomic oxygen resulting from equilibrium dissociation of the oxygen molecule is shown through reaction $[1]^{2}$ as $p(O)=1.76 \times 10^{-7}$ atm indicating that reactions with atomic oxygen are not significant. The evaporation reactions [2], [3], and [4] show that sodium in the oxidation atmosphere is present as both atomic ( $\mathrm{Na}$ ) and molecular $\left(\mathrm{Na}_{2} \mathrm{O}, \mathrm{NaO}\right)$ species. Reaction [5] shows the conversion of $\mathrm{Na}_{2} \mathrm{O}$ into $\mathrm{NaO}$ through interaction with oxygen. These results indicate that in a dry oxidation atmosphere atomic sodium is about three times more abundant than molecular sodium compounds. The total number of sodium atoms in the equilibrium oxidation atmosphere is $1.2 \times 10^{7} \mathrm{~cm}^{-3}$ (both atomic and molecular species included).

Table II shows the equilibrium atmosphere resulting in fused silica oxidation tubes at $1300^{\circ} \mathrm{K}$ when water is added. ${ }^{3}$ The reaction system [7] shows that water is more stable than $\mathrm{OH}$ by factors ranging from 20 to more than 100 times as humidity in the oxidation ambient increases. For increasing water content the most significant changes are seen in $p\left(\mathrm{Na}_{2}(\mathrm{OH})_{2}\right)$ and $p(\mathrm{NaOH})$ as resulting from reactions [8] through [11]. The sodium number density for $1 \mathrm{ppm}$ water impurity goes to $3.3 \times 10^{8} \mathrm{~cm}^{-3}$ or a factor 27 higher than the dry oxidation condition. If $30 \mathrm{ppm}$ water is present in the oxidation ambient the sodium number density at equilibrium raises to $1.7 \times 10^{9} \mathrm{~cm}^{-3}$ or a factor 142 higher than the dry oxidation condition. Table III and Fig. 1 summarize these results ${ }^{4}$

The above calculations show that sodium contamination developed in oxidation atmospheres could be explained in terms of contamination in the bulk fused silica even if the furnace tube wall surface were perfectly clean. To reduce sodium density in oxidation atmospheres, it is necessary that the bulk tube material itself be sodium free. Two different approaches have been tried: (i) use of a sodium-free tube wall,

1 Ail calculated values presented In this work refer to equllib. rium conditions and represent ilmiting values for the actual sys. tems because of klnetic and difuslon factors.

$\because$ Data used to calculate reactlon equlibrium constants are ilsted in Table V11. The actuai caiculation scheme ls illustrated in the Appendix.

"Experlmental evldence shows that in a typlcal "dry" oxidation atmosohere the water content is in the $20-30 \mathrm{ppm}$ range (i4). Moreover at oxidation temperatures in the range $900^{\circ} \cdot 1300^{\circ} \mathrm{C}$ it was reported that water and/or hydrogen from the external ambient can diffuse through the silica tube wail into the oxldation chamber (15).

- Because of errors and approximations Involved in thermody. namic data used to evaluate the equilibrium results, an absolute error of $\pm 50 \%$ could be expected in these calculations. The relahe was ed that in open fused silca oxidation tubes no free sollum was detected waterms of calculations shown In Fig. 1. For sufficlently hlgh water content in the oxidation atmosphere the amount of free sobe substantially reduced due to sodium reactivity with excess water. Thus, free sodium is converted into compound sodlum and consequently becomes not detectable by the above-mentioned technique. $\kappa$

$1.76 \times 10^{-7}$

$7.9 \times 10^{-3-10}$

$2.5 \times 10^{-10}$
$9.1 \times 10^{-30}$

$\left.\begin{array}{l}0.42 \\ 3.3 \times 10-31\end{array}\right\}$

\begin{tabular}{|c|c|}
\hline$p($ atm $)$ & $N\left(\mathrm{~cm} \cdot{ }^{3}\right)$ \\
\hline $\begin{aligned} g(O) & =1.76 \times 10^{-7} \\
p(\mathbb{N a} 0) & =7.9 \times 10^{-5} \\
p(\text { Na }) & =1.6 \times 10^{-1 .}\end{aligned}$ & $8 \times 10^{4}$ \\
\hline$p(\mathrm{NaO})=5.7 \times 10^{-15}$ & $3.2 \times 10^{\circ}$ \\
\hline
\end{tabular}

Total sodium density: $1.2 \times 10^{n}$

or (ii) use of sodium-leaching agents to deplete a region just under the inner wall surface prior to oxidations. The first approach is based on the well-known fact that polycrystalline silicon tubes can be produced with 1000 times less sodium content than found in silica tubes (17). Empirical results indicate that oxide films grown on silicon using recently installed silicon oxidation tubes produce cleaner films (lower sodium content) than similar oxides prepared in fused silica tubes.

Polycrystalline silicon tubes develop, however, observable sodium contamination after being in operation for several months, when the use of sodium-leaching agents is then required. This contamination, developed under strictly controlled production-oriented environments, could be explained by assuming that during tube operation at oxidation temperature sodium arising from external sources reaches the oxidation chamber by diffusion through the tube wall. The contamination source could be located in furnace refractories surrounding the oxidation tube (11). Once the tube wall becomes loaded with sodium above a critical level, evaporation into the oxidation atmosphere starts to fredominate. This is a slow process that may take a long time (several months) in continuous operation depending on environmental conditions (18)

\section{Reactions Occurring When Cleaning Fused} Silica Tubes

Cleaning of oxidation tubes is a frequent operation in processing facilities. At room temperature, the clean-

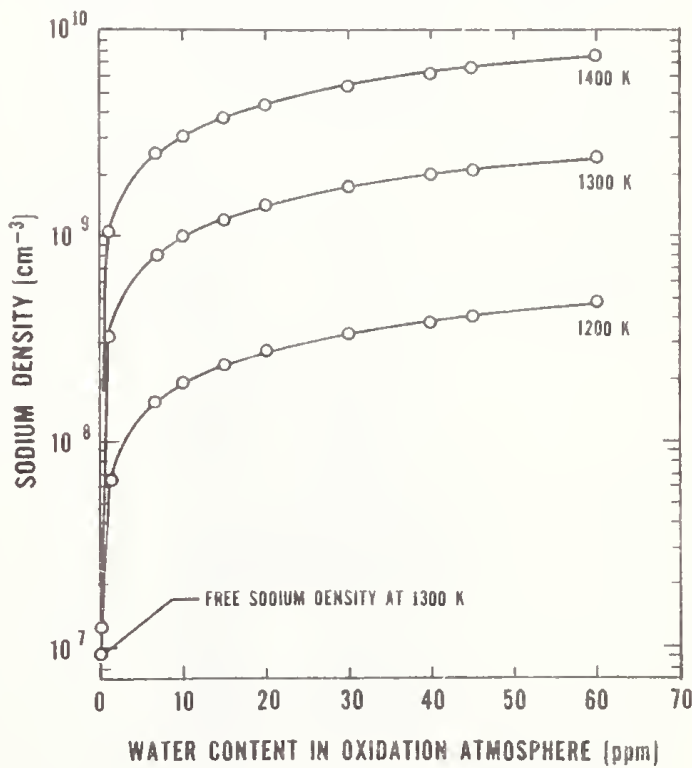

Fig. 1. Total sodium density $\left[\mathrm{cm}^{-3}\right]$ of equilibrium in fused silica oxidation tube armosphere os a function of temperature and water impurity. The sodium concentration in silico is assumed 10 $\mathrm{ppm}, \mathrm{p}\left(\mathrm{O}_{2}\right)$ is $1 \mathrm{~atm}$ 


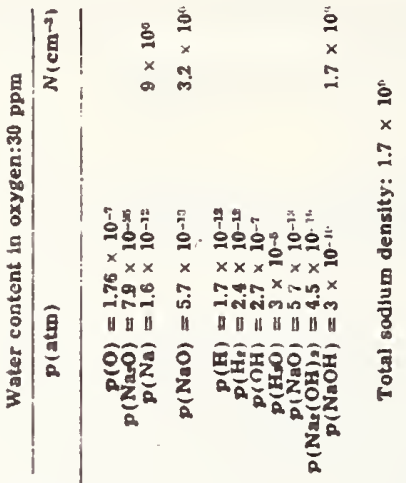

ing can be accomplished using conventiunal acid solutions. At oxidation temperatures, the cleaning is made in situ by using $5-10 \%$ chlorine or hydrogen chloride diluted in an inert gas carrier This treatment removes sodium contained in the tube inner "skin" down through a convenient depth. A typical cleaning action of this kind requires up to $20 \mathrm{hr}$ of continuous treatment flushing the cleaning gas at about $4 \mathrm{~cm}^{3} /$ sec $\left(0.5\right.$ std $\left.\mathrm{ft}^{3} / \mathrm{hr}\right)$. The several reactions taking place during this process are summarized in Table IV

Reactions [16], [17], and [18] are solved as a simultaneous system. The resulting sodium number density at equilibrium in the tube atmosphere goes to $8.8 \times$ $10^{16} \mathrm{~cm}^{-3}$ or a factor $7.3 \times 10^{9}$ higher than the equilibrium sodium number density in a dry oxidation atmosphere. Reactions [16], [19], and [20] show similar results due to hydrogen chloride cleaning. The increase in sodium number density with respect to the dry oxidation condition is also in the $10^{9}$ range. Microdroplets of liquid sodium chloride, if formed on the tube wall hot zone, would be removed by the gas stream and transported to a cooler tube zone where sodium chloride precipitates on the wall (sodium chloride melts at $801^{\circ} \mathrm{C}$ ). This "transpiration mechanism" continues while sodium in the hot zone is available for reaction. It should be mentioned that sodium chloride formed in the gas phase is carried down the flushing gas stream and condenses also at the cooler zone where the temperature is appropriate. The cleaning action can be interpreted in terms of relocating sodium in the tube, depleting the hot zone, and enriching the exhaust tube end where the wall temperature is appropriate for condensation.

Stoichiometric equilibria in reactions [17] through [20] require the use of about $1.5 \mathrm{~g}$ of clilorine or hydrogen chloride per gram of extracted sodium. Assuming that the oxidation tube wall surface is about $4000 \mathrm{~cm}^{2}$ and the reaction depth in the wall is $10^{-3}$ $\mathrm{cm}$, the total reacting volume is $4 \mathrm{~cm}^{3}$ or about $10 \mathrm{~g}$ fused silica. Assuming $10 \mathrm{ppm}$ sodium content in the fused silica, the amount of sodium reacting is $10^{-4} \mathrm{~g}$ which requires the use of $1.5 \times 10^{-4} \mathrm{~g}$ of chlorine or hydrogen chloride for complete reaction equilibrium The density of $10 \%$ chlorine at $1300^{\circ} \mathrm{K}$ is $6.74 \times 10^{\circ}$ $\mathrm{g} / \mathrm{cm}^{3}$. At $4 \mathrm{~cm}^{3} / \mathrm{sec}$ flow, the chlorine mass transported through the oxidation tube is $2.7 \times 10^{-4} \mathrm{~g} / \mathrm{sec}$ This shows that the reaction rate is regulated by diffusion of sodium in the fused silica. When sodium in the wall bulk diffuses to the wall sulface, the reaction with chlorine takes place iminediately. In practicte. a cleaning period of about $20 \mathrm{hl}$ is used to deplete the tube wall. The longer the rleaning period, the longer the oxidation tube can latel be operated under acceptable oxide growing colıditions. These calculations indicate that the amount of sodium removed from the fused silica tube wall through chlorine or hydrogen chloride cleaning is substantial and that such cleaning certanly reduces the sudiun content in the inner tube wall surface

Iodine or hydrogen iodide call alsu be used for in silu oxidation tube cleaning The 1 elevant reactions takıng place are summarized in Table $V$. Reactions [25] through [28] show the effectiveriess of this type of cleaning indicatıng that todine or liydiogen todide could be used instead of chlorilie ol hydrugen chloride. However, due to econonic reasons, the latter are more extensively used in practice. Since thermodynamic data are not avalable $L$, the desired extent, similar calculations are nut presented here for bromine and hydrogen bronude Howevel bronine should have an intermediate behavior between, clilorine and iodine according to the pattern of the nuenubers of the halogen family. 
Toble III. Equilibrium sodium densities in fused silico oxidotion ambient ot $1300^{\circ} \mathrm{K}$. Oxygen at $1 \mathrm{~atm}$.

\begin{tabular}{|c|c|c|c|c|c|c|}
\hline \multirow[b]{2}{*}{ Compound } & \multicolumn{2}{|c|}{ Water content in oxygen: 0} & \multicolumn{2}{|c|}{ Water content in oxygen: I ppm } & \multicolumn{2}{|c|}{ Water content in oxygen: $30 \mathrm{ppm}$} \\
\hline & $p(a t m)$ & $N\left(\mathrm{~cm}^{-8}\right)$ & $p(a t m)$ & $N\left(\mathrm{~cm}^{-3}\right)$ & $p(a t m)$ & $N\left(\mathrm{~cm}^{-8}\right)$ \\
\hline $\begin{array}{l}\mathrm{Na} \\
\mathrm{NaO} \\
\mathrm{NaO} \\
\mathrm{NaOH} \\
\text { Nas (OH), } \\
\text { Sodium num }\end{array}$ & $\begin{array}{c}1.8 \times 10^{-28} \\
5.7 \times 10^{-13} \\
7.9 \times 10^{-200} \\
= \\
=\end{array}$ & $\begin{array}{c}9 \times 10^{\circ} \\
3.2 \times 10^{4} \\
= \\
1.2 \times 10^{7}\end{array}$ & $\begin{array}{l}1.6 \times 10^{-29} \\
5.7 \times 10^{-10} \\
7.8 \times 10^{-28} \\
5.6 \times 10^{-11} \\
1.5 \times 10^{-20}\end{array}$ & $\begin{array}{l}9 \times 10^{\circ} \\
3.2 \times 10^{\circ} \\
3.2 \times 10^{\circ} \\
3.3 \times 10^{93}\end{array}$ & $\begin{array}{l}1.6 \times 10^{-12} \\
5.7 \times 10^{-13} \\
3 \times \overline{10}^{-10} \\
4.5 \times 10^{-20}\end{array}$ & $\begin{array}{l}9 \times 10^{6} \\
3.2 \times 10^{5} \\
1.7 \times 10^{9} \\
1.7 \times 10^{9}\end{array}$ \\
\hline
\end{tabular}

Toble IV. Equilibrium reoctions in fused silico tubes ot $1300^{\circ} \mathrm{K}$ when cleoning with $10 \%$ $\mathrm{Cl}_{2}$ or $\mathrm{HCl}$ in $\mathrm{N}_{2}$ corrier of 1 otm.

\begin{tabular}{|c|c|c|c|c|}
\hline & Reaction & $\boldsymbol{K}$ & $p(\mathrm{~atm})$ & $N\left(\mathrm{~cm}^{-3}\right)$ \\
\hline [12] & $\mathrm{Cl}(\mathrm{g}) \Rightarrow 2 \mathrm{Cl}(\mathrm{g})$ & $1.6 \times 10^{-6}$ & $P(C I)=4 \times 10^{-8}$ & \\
\hline (13) & $\mathrm{HCl}(8) \rightarrow \mathrm{H}(\mathrm{g})+\mathrm{Cl}(\mathrm{g})$ & $1 \times 10^{-13}$ & $p(\mathrm{HCC}) \cong 0.11$ & \\
\hline $\begin{array}{l}{[14]} \\
{[15]} \\
{[16]} \\
{[17\}} \\
{[18]}\end{array}$ & 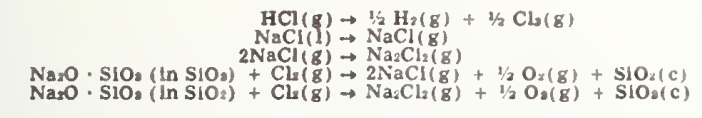 & $\left.\begin{array}{r}7.5 \times 10^{-5} \\
1.25 \times 10^{-2} \\
27.1 \\
6.4 \\
174\end{array}\right\}$ & $\begin{aligned} p(\mathrm{Cl}) & =75 \times 10^{-6} \\
p(\mathrm{NaCl}) & =1.25 \times 10^{-2} \\
p(\mathrm{NaCl}) & =1.01 \times 10^{-2} \\
\mu\left(\mathrm{NaCl}_{2}\right) & =2.76 \times 10^{-3} \\
p\left(\mathrm{O}_{2}\right) & =3.9 \times 10^{-3}\end{aligned}$ & $\begin{array}{c}\text { (vapor pressure) } \\
5.7 \times 10^{10} \\
3.1 \times 10^{10}\end{array}$ \\
\hline $\begin{array}{l}{[16]} \\
{[19]} \\
{[20]}\end{array}$ & 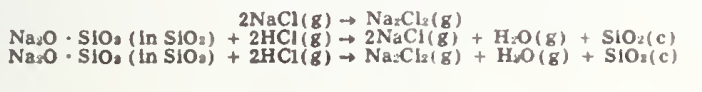 & $\left.\begin{array}{c}27.1 \\
0.42 \\
11.4\end{array}\right\}$ & $\begin{array}{l}P(\mathrm{NaCC})=4.1 \times 10^{-3} \\
p(\mathrm{NaCl})=4.6 \times 10^{-4} \\
p(\mathrm{HbO})=2.3 \times 10^{-8} \\
\text { Sodlum number density }\end{array}$ & $\begin{array}{l}6.6 \times 10^{10} \\
2.3 \times 10^{16} \\
2.6 \times 10^{10}\end{array}$ \\
\hline
\end{tabular}

Toble V. Equilibrium reactions in fused silico tubes ot $1300^{\circ} \mathrm{K}$ when cleaning with $10 \%$ $\mathrm{I}_{2}$ or $\mathrm{HI}$ in $\mathrm{N}_{2}$ corrier of $\mathrm{I}$ otm.

\begin{tabular}{|c|c|c|c|c|c|}
\hline & & Reaction & K & $p(\operatorname{atm})$ & $N\left(\mathrm{~cm}^{-\infty}\right)$ \\
\hline (21) & & $1 / 2 I_{z}(\mathrm{~g}) \rightarrow 1(\mathrm{~g})$ & 0.467 & $p(1)=1.0 \times 10^{-1}$ & \\
\hline [22] & & $2 H I(g) \rightarrow H u(g)+L_{2}(g)$ & 0.0501 & $p(1)=3.57 \times 10^{--}$ & \\
\hline (23) & & $2 \mathrm{HI}(\mathrm{g}) \rightarrow \mathrm{H}_{3}(\mathrm{~g})+2 \mathrm{I}(\mathrm{g})$ & 0.0109 & $p\left(\mathrm{H}_{2}\right)=2.36 \times 10^{-2}$ & \\
\hline $\begin{array}{l}{[24]} \\
{[25]} \\
{[26]}\end{array}$ & $\begin{array}{l}\mathrm{NanO} \cdot \mathrm{SiO}\left(\ln \mathrm{SiO}_{2}\right) \\
\mathrm{Na}+\mathrm{O} \cdot \mathrm{SLO}\left(\ln \mathrm{SiO}_{2}\right)\end{array}$ & $\begin{aligned} \mathrm{Nal}(1) & \rightarrow \mathrm{Nal}(\mathrm{g}) \\
+\mathrm{L}(\mathrm{g}) & \rightarrow 2 \mathrm{Nal}(\mathrm{g})+1 / 2 \mathrm{O}_{2}(\mathrm{~g})+\mathrm{SlO}_{2}(\mathrm{c}) \\
+21(\mathrm{~g}) & \rightarrow 2 \mathrm{Nal}(\mathrm{g})+1 / 2 \mathrm{O}_{2}(\mathrm{~g})+\mathrm{SlO}_{2}(\mathrm{c})\end{aligned}$ & $\left.\begin{array}{l}7.06 \times 10^{-2} \\
9.3 \times 10^{-8} \\
4.3 \times 10^{-1}\end{array}\right\}$ & $\begin{array}{l}p(\mathrm{Na1})=7.06 \times 10^{-2} \\
p(\mathrm{NaI})=9.3 \times 10^{-3}\end{array}$ & (vapor pressure) \\
\hline $\begin{array}{l}{[27\}} \\
{[28\}}\end{array}$ & 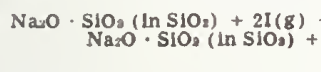 & $\begin{aligned}+\mathrm{H}_{2}(\mathrm{~g}) & \rightarrow 2 \mathrm{Nal}(\mathrm{g})+\mathrm{H} \cdot \mathrm{O}(\mathrm{g})+\mathrm{SlO}_{2}(\mathrm{c}) \\
+2 \mathrm{HI}(\mathrm{g}) & \rightarrow 2 \mathrm{Nal}(\mathrm{g})+\mathrm{H}_{2} \mathrm{O}(\mathrm{g})+\mathrm{SlO}_{3}(\mathrm{c})\end{aligned}$ & $\left.\begin{array}{c}4.9 \times 10^{3} \\
54.2\end{array}\right\}$ & $\begin{array}{l}p(\text { NaI })=1.4 \times 10^{-3} \\
\text { Sodium number density }\end{array}$ & $7.9 \times 10^{10}$ \\
\hline
\end{tabular}

- $p\left(\mathrm{Na}_{2} \mathrm{I}_{2}\right)$ can be estlmated about $0.5 \mathrm{p}(\mathrm{NaI}$, from similar results obtatned with the chlorine system. No thermodynamic data are avall. able for $\mathrm{Na}_{2}$.

\section{The Oxidation Atmosphere as a Sodium Contamination Source}

An experimental test was made to check the validity of assuming that sodium becomes trapped in an oxidation tube due to the evaporation-transpiration-condensation cycle mentioned above. In a fused silica tube operated at $1000^{\circ} \mathrm{C}$ "dry" oxygen ${ }^{5}$ was allowed to flow at a rate of $4 \mathrm{~cm}^{3} / \mathrm{sec}$ for $120 \mathrm{hr}$. The exhaust gas was passed through a $5 \%$ hydrochloric acid solution. After this period the solution was analyzed by flame emission spectrometry. The detection limit for sodium in the solution was $10^{-10} \mathrm{~g} / \mathrm{cm}^{3}$. No evidence of sodium was detected in the solution after correcting for evaporation of the liquid. This test was repeated twice with consistently negative results. Consequently, it was concluded that sodium is not carried out of the oxidation tube.

There is no apparent way of extracting from a furnace tube a representative sample of the oxidation atmosphere. Other analytical techniques operating on gas samples removed from the oxidation atmosphere, such as mass spectrometry, are not appropriate to detect sodium due to condensation as the temperature decreases. On the other hand, any analytical instrumentation if introduced into the oxidation tube could change the oxidation atmosphere equilibrium adding extra contamination, thus perturbing the measurements.

5 Electronic grade oxygen typlcally contains about 5 ppm water and $20 \mathrm{ppm}$ hydrocarbons measured as methane.

\section{Contamination of Thermally Grown Silicon Dioxide Films}

The results of Tables I and II indicate that in typical fused silica oxidation tubes the equilibrium atmosphere contains atomic and molecular sodium species resulting in a sodium number density in the $10^{7}-10^{9} \mathrm{~cm}^{-3}$ range, depending on the amount of water present. Due to the low density, sodium atoms and molecules contained in the oxidation ambient can be considered as ideal gases. The number of collisions per unit time sodium executes per unit area on the wafer surface is expressed as (19)

$$
\nu=0.25 \mathrm{Nv}
$$

where $N$ is the sodium number density in the oxidation atmosphere, $v=(8 \mathrm{kT} / \pi \mathrm{m})^{3 / 3}$ is the average molecular velocity at temperature $T, k$ is the Boltzmann constant, and $m$ is the weight of the sodium species. The resulting value of $\nu$ for $T=1300^{\circ} \mathrm{K}$ is $10^{12} \mathrm{~cm}^{-2} \cdot \mathrm{sec}^{-1}$ for $N=5 \times 10^{7} \mathrm{~cm}^{-3}$. The presence of oxygen (1 atm) in the tube slightly modifies this number due to collisions with sodium atoms and molecules.

A number of reactions can take place between the growing silicon dioxide film and the impinging sodium molecules as shown in Table VI. Sodium silicate is formed by reactions [29] through [35] which have high equilibrium constants. As sodium from the oxidation atmosphere becomes incorporated into the oxide 
Table VI. Impurity reactions with $\mathrm{SiO}_{2}$ films in fused silico oxidation tube otmospheres at $1300^{\circ} \mathrm{K}$

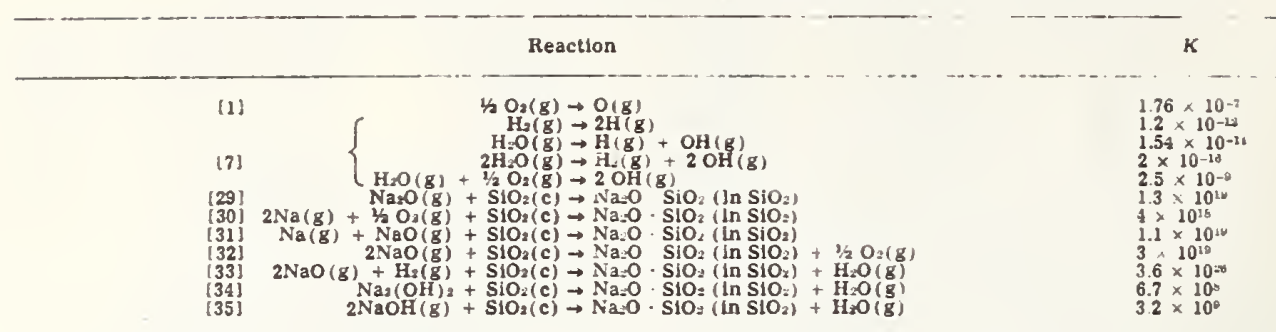

film, more sodium from the tube wall evaporates into the atmosphere, maintaining the equilibrium.

There are not enough kinetic data available to estimate precisely the actual amount of sodium incorporated into the silicon dioxide film during the oxidation cycle. The typical dry oxidation period used to grow a $100 \mathrm{~nm}$ thick oxide film on a (100) sample of silicon at $1000^{\circ} \mathrm{C}$ is about $200 \mathrm{~min}$. During this period the oxide film is subjected to about $10^{16}$ sodium collisions per square centimeter. Parameters such as the wafer temperature, oxygen flow, and the water content in the tube certainly influence the oxide film contamination level At equilibrium, the sodium concentration in the oxide film grown on silicon should be similar to that in the oxidation tube wall bulk, i.e., $10 \mathrm{ppm}\left(\sim 10^{17} \mathrm{~cm}^{-3}\right)$. This consideration clearly establishes that dry oxidation of silicon made in fused silica tubes produces oxide films with a significant amount of sodium included; the upper limit is determined by the impurity level in the fused silica bulk. Whether or not this sodium which has chemically reacted with silica to form sodium silicate in the film (Table VI) infuences the electrical and radiation properties of MOS devices is a matter that needs detailed examination.

It has been reported that structurally included sodium atoms in silicon dioxide films behave like immobile ionic contamination. Capacitance measurements on MOS capacitors with a dielectric of silicon dioxide doped with sodium to density of $10^{20} \mathrm{~cm}^{-3}$ showed that most of the included sodium is inactive from the viewpoint of both surface-state density and ionic migration under high electric field at elevated temperature (15). However, instability of semiconductor devices due to sodium mobility in thermal silicon dioxide films has been largely recognized as a central problem in semiconductor technology. Sodium was shown to cause instability under bias-temperature stress in silicon devices made by planar technology. Thermally stimulated ionic conductivity measurements made on MOS capacitors using aluminum or gold as the gate metal have shown that in sodium-doped gate oxide films with surface concentrations in the $10^{11}-10^{13} \mathrm{~cm}^{-2}$ range, sodium moves at temperatures above $200^{\circ} \mathrm{C}$ under electric flelds as low as $12 \times 10^{5} \mathrm{~V} / \mathrm{cm}(20)$

In practice instabilities due to sodium can be eliminated either by stringent cleanliness during oxide processing or by the formation of a protective layer such as phosphosilicate glass which can trap sodium (20).

An experimental test was made in a carefully controller fused silica tube operated at $1000^{\circ} \mathrm{C}$ and periodically cleaned in situ with chlorine. Silicon dioxide films $50-100 \mathrm{~nm}$ thick were grown on (100) n-type silicon surfaces using dry electronic grade oxygen and annealed in situ after oxidation in dry nitrogen for $30 \mathrm{~min}$. The metal gate was applied by evaporation of $1 \mu \mathrm{m}$ thirk aluminum film in an electron-gun evaporator. MOS capacitors were prepared and capacitance measurements were made at room temperature before and after stressing the capacitors at $300^{\circ} \mathrm{C}$ for $5 \mathrm{~min}$ with electric field of $10^{6} \mathrm{~V} / \mathrm{cm}$ (2). The results indicate a clear correlation between cleaning of the fused silica oxidation tube and the total mobile ion surface density in the oxide film. These measurements indicate that oxide films grown in recently cleaned tubes show mobile ion densities in the $10^{10}$ $\mathrm{cm}^{-2}$ range.

Assuming uniform contamination film in the measurements, these "clean" oxides exhibit an impurity number density in the $10^{15} \mathrm{~cm}^{-3}$ range. This contamination level is caused by impurities accumulated during the device preparation process. It has been shown that radiation sensitivity of gate oxide films has no correlation with the mobile ion content in the oxide as measured by MUS capacitance measurements after bias temperature stressing or high temperature ramping (21) However a correlation of total sodium content with radiation sensitivity in the oxide of various MOS devices has been reported (22). These considerations suggest that sodium contamination introduced in the oxide film during oxidation and metallization may' play a prominent role in determining the device radiation resistance. Phosphorus gettering of the gate region or hydrochloric acid passivation in creases the radiation sensitivity of MOS devices. Hence to obtain reliable, radiation-stable MOS devices in the absence of gettering it has been suggested that high standards of cleanliness should be maintained (21). This is specially applicable to the oxidation step. Alkali impurity introduced through metailization should also be minimized by careful investigation of the mechanisms through which such contamination is introduced.

\section{Conclusions}

The results of the present thermodynamic calculations show that sodium included in the bulk of fused silica oxidation tubes is a significant source of contamination in oxıdation atmospheres, even it sodium surface contamination produced hy external agerts in the tube is negligible. The presence of water in the oxidation atmosphere produces a rapid bulldup of the sodium number density from the $10^{7} \mathrm{~cm}^{-3}$ range, corresponding to dry oxidation, of up to two orders of magnitude greater for water concen'rations of a few parts per million. During the oxidation cycle, sodium is incorporated into the oxide film as sodium silicate developing a significarit contamination level which can be potentially harmful for MOS device radiation resistance. Watel may be incorporater in the oxidation atmosphere through trace vater or hy. drogen from hydrocarbon impurities included in nxygen, and by ambient water that diffused into the oxidation chamber through the fus d silica tube wall.

Preparation of clean oxide films reutuires the conirnl of sodium impurity in the oxidation atinosnhere This in turn imposes a strict control of the tube male:ial and appropriate care conrerning the eluvilunmeridfl conditions during wafer processing.

\section{Acknowledgment}

Thanks are due to $T$ C. Rains from the Analytical Chemistry Division for the results on flame emission 
spectrometry. The collaboration of T. F. Leedy and R. Y. Koyama of the Electronic Technology Division in preparing MOS capacitors and in measuring their electrical properties is highly appreciated. This work was conducted as part of the Semiconductor Technology Program at the National Bureau of Standards and was supported in part by the Defense Nuclear Agency (IACRO 76-816) and the NBS.

Manuscript submitted Aug. 3, 1976; revised manuscript received Dec. 20, 1976.

Any discussion of this paper will appear in a Discus sion Section to be published in the December 1977 JourNal. All discussions for the December 1977 Discussion Section should be submitted by Aug. 1, 1977.

Publication costs of this article were assisted by the National Bureau of Standards.

\section{APPENDIX}

Colculation of Equilibrium Reoction Constant from JANAF Doto

For a reaction $\mathrm{xX}+\mathrm{y} \mathrm{X} \rightarrow \mathrm{wW}+\mathrm{zZ}$ the thermodynamic equilibrium constant may be written as

$$
K=\frac{\alpha^{W}(W) \cdot a^{z}(Z)}{\alpha^{x}(X) \cdot \alpha^{3}(Y)}
$$

where $\alpha(X)$ is the activity of compound $X$. For calculations involved in this work (dealing with very dilute gaseous species), the activity may be taken as the partial pressure of the vapor phase (measured in atmospheres). The activity of a solid phase such as $\mathrm{SiO}_{2}$ (c) is taken by convention as unity. For $\mathrm{Na}_{2} \mathrm{SiO}_{3}$ solid solution in $\mathrm{SiO}_{2}$ the activity is taken

Toblo VII. JANAF thermodynamic dato used to calculate equilibrium conditions of $1300^{\circ} \mathrm{K}$ for reoctions listed in Tobles I-VI

\begin{tabular}{|c|c|c|}
\hline Compound & $\underset{(\mathrm{kcal} / \mathrm{mole})}{\Delta H^{\circ} \mathrm{smo} 0^{\circ}}$ & $\begin{array}{c}-\left(G^{*} \mathrm{~T} \vec{H}^{H^{\circ}} \text { (cal) }\right) / T^{\circ} \\
\text { (cal/ } \mathrm{K} \text { mole })\end{array}$ \\
\hline 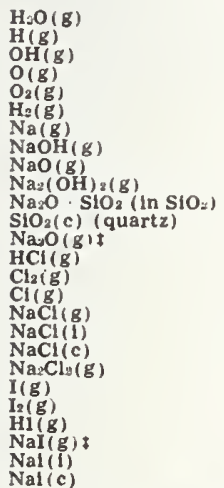 & $\begin{array}{c}-57.798 \\
52.18 \\
9.432 \\
59.559 \\
0 \\
0 \\
25.755 \\
-50.4 \\
20.0 \\
154.6 \\
-376.8 \dagger \\
-217.7 \\
8.7 \\
-22.063 \\
0 \\
28.922 \\
-43.36 \\
-92.237 \\
-96.26 \\
-135.3 \\
25.537 \\
14.924 \\
6.3 \\
-22.7 \\
-63.695 \\
-88.6\end{array}$ & $\begin{array}{l}51.136 \\
30.879 \\
48.677 \\
42.044 \\
54.283 \\
36.130 \\
40.201 \\
63.766 \\
60.696 \\
89.141 \\
50.565 \\
19.918 \\
72.3 \\
49.624 \\
59.316 \\
43.228 \\
61.099 \\
32.199 \\
26.479 \\
91.387 \\
46.671 \\
68.559 \\
54.425 \\
64.8 \\
36.532 \\
32.656\end{array}$ \\
\hline
\end{tabular}

$\therefore \Delta H^{\circ}$ res $=$ standard enthalpy of formation.

$\because\left(G^{\circ} T-H^{\circ} * x_{0}\right) / T=$ Glbbs energy function in the standard state at temperature $1300^{\circ} \mathrm{K}$

i The value of $\Delta H^{\circ}$ iso for $\mathrm{Na}_{2} \mathrm{O} \cdot \mathrm{SIO}_{2}$ (in $\mathrm{SiO}_{8}$ ) was calculated using the equllibrium constant from reaction [3] Table I (see Ref. (121). The free energy function was assumed to be that of a. $\mathrm{SIO}_{2}$ (gls) given by the JANAF tables.

: The $\mathrm{Na} 2 \mathrm{O}$ data were estimated from varlous lithium, sodlum, and potassium oxidea data given in the JANAF tables. The Na as the mole fraction ( 105 in the present work) Fur the reaction

$$
\mathrm{Na}_{2} \mathrm{O} \cdot \mathrm{SiO}_{2} \text { (gls) + } 1 / 2 \mathrm{O}_{2}(\mathrm{~g}) \rightarrow 2 \mathrm{NaO}(\mathrm{g})+\mathrm{S}_{1} \mathrm{O}_{2}(\mathrm{l})
$$

the equilibrium constant is expressed as

$$
K=p^{2}(\mathrm{NaO}) \times 10^{5} / p^{1 / 2}\left(\mathrm{O}_{2}\right)
$$

To evaluate $K$ at a particular temperature $T$ imea. sured in Kelvin) the following relations are used

$$
\begin{gathered}
\Delta G_{\mathrm{T}}=-R T \ln K \\
\Delta G_{\mathrm{T}}=\Delta H^{\circ}{ }_{298}+T\left(\Sigma\left(G^{\circ}{ }_{\mathrm{T}} \quad H^{\circ}{ }_{29 \mathrm{H})}\right) / T\right)
\end{gathered}
$$

where $\Delta H^{\circ}{ }_{298}$ is the heat of reaction, calculated from standard heats of formation as

$\Delta H^{\circ}{ }_{\text {g298 }}=\Sigma \Delta H^{\circ}{ }^{\circ} 298$ (products) $-\Sigma \Delta H^{\circ}{ }^{\circ}{ }^{208}$ (reactants)

$[\mathrm{kcal} / \mathrm{mole}\rfloor$

and $\Sigma\left(G^{\circ} \mathrm{T}-H^{\circ}{ }_{298}\right) / T$ is calculated from Gibbs energy function in the standard stalt al temptiature $T$

$\Sigma\left(G^{\circ} T-H^{\circ}{ }_{298}\right) / T=\left\{\Sigma\left(G_{T}^{\sim}-H^{\circ}{ }_{248}\right) / T\right\}_{\mu r u d u \cdot T S}$

$$
\text { - }\left\{\Sigma\left(G_{\mathrm{T}}-H_{29 g}\right) / T_{i} \text { reactants }[\text { cal/ } \mathrm{K} \text { mole }]\right.
$$

Thls calculation follows standard thermodyuamli formalism Isee Ref (23)] REFERENCES

1. S. Schlegal, IEEE Trans Électrun Dences, ed-14 728 (1967), ibid., ed-15, 951 ( 1968 ,

2. K. H Zaininger RCA Rev., 27, 341 (1966).

3. R. J. Kriegler, "12th Annual Pruceedings, Reliability Physics 1974," IEEE Catalog No 74CHO839-1 PHY, pp. 250-258 (1974)

4. B. Yurash and B Deal. Thas Journul, 115. 1191 (1968).

5. W. R. Knolle, ibid. 120,987, 1973)

6. W. R. Knolle and T F. Ketajczyk, J1, 2bid. 120. 1106 (1973)

7. K. G. Aubuchon, IEEE Trans Nucl Sci., ns-18, No. 6. 117 (1971)

8. G. Hetherinneton (; W. Stephenson, and J A. Winterburn, k'lectronw Eng., 41, No 49b, 52 (1969). ibid., 41, No. 496, 44 (1969)

9. A E. Owen and R. W Douglas. I Sis Glass Tech. nol., 43, 159T (1959)

10. H. F. Wolf, "Silicon Semiconductor Data." pp 526527, Pergamon Press. Oxford (1969)

11. D. R. 'Fewer and W. L. Gill, Tech Rep. No. RADC. TR-66-345, pp. 33-49 (1966); dilso available as NTIS Document AD-489-969

12. G. L. Vidale, General Electric Cu. Technical lnformation Series, R60SD390 (1960)

13. JANAF Thermochemical Tables $D R$ Stull and H. Prophet, Editors, 2nd ed. NSRDS-NBS 37 (1971).

14. E. A. Irene, This Journal, 121, 1613 (1974)

15. A. G. Revesz and R. J. Evans. J. Phys Chem Solids, 30, 551 (1969),

16. S. Mayo, R. A. Keller, J. C. Travis, and R. B Green. J. Appl. Phys., 47, 4012 (1976).

17. W. Dietze, L. P. Hunt, and D. H Sawyer, This Journal, 121, 1112 (1974).

18 D H. Sawyer, Private comnunicution.

19. S. Dushman "Scientıfic Foundations of Vacuum Technique," 2nd ed., p. 14, John Wiley \& Sons, Inc., New York (1962).

20. T. W. Hickmott, Appl. Phys Lett. 22267 (1973): Phys. Rev. Lett., 32, 65 11974), J. Appl. Phys. 46. 2583 (1975)

21. B. L. Gregory, IEEE Trans. Nacl Si?., ns-22. No. b. 2295 (1975)

22. H. Hughes, R. D Baxter, and B. Plullsps, ibid. ns-19, No. 6, 256 (1972).

23. G N Lewis and M. Randall "Thermudynamics, 2nd ed., chap. 15, M.Graw Hil] Book Co., NeW York (1961). 

Appendix 3

\author{
Reprinted from Journal of the Electrochemical Society \\ Vo1. 125, No. 1, January 1978 \\ Printed in the U.S.A.
}

\title{
Thermodynamic Considerations in the Use of Polysilicon Oxidation Tubes for Clean $\mathrm{SiO}_{2}$ Film Preparation
}

\author{
Santos Mayo ${ }^{*}$ \\ National Bureau of Standards, Electronic Technology Durision. \\ Institute for Applied Technology, Washington, D.C. 20234 \\ and William $H$. Evans \\ National Bureau of Standards. Physical Chemistry Division, \\ Institute for Matertals Research, Washington, D.C. 20234
}

\begin{abstract}
The thermodynamic equilibria established in oxidation atmospheres in polycrystalline silicun tubes operated at $1000^{\circ} \mathrm{C}$ are analyzed Silicon oxidation tubes nade by chemical vapor deposition through hydrugen reduction of pure trichlorosilane have very low sodium content (about $10 \mathrm{ppb}$ or 1000 times less sodium than in transparent fused silica oxidation tubes). Due to the low sodium content in new oxidation tubes, clean (low alkali content) thermal oxide films can be grown on silicon wafers. However, tube contamination developed during semiconductor processing operations imposes the need for appropriate periodıc tube cleaning to maintaun sodium contamination in the oxidation atmosphere within acceptable levels. Tube cleaning reactions taking place at oxidation temperature are discussed showing that the quality of thermal oxide films is influenced by tube cleaning efficiency.
\end{abstract}

Preparation of thermally grown clean oxide films on ilicen iwates has great technnlıgical impact on succesif. $\cdots$ matroelectronic device fabrication. Although

- Ejactr.xisemical Society Active Member. Key words: alkall contamination, clean $\mathrm{SiU}_{2}$ firm, microelec. sronic deilce rreparation. Mos structures. the understanding of the role played by alkali lons in such films is not complete, especially cuncerning the behavior of electrically "ditıve" and "inactive" contamunation (1), the presence of alkall species in thermally grown silicon dioxıde films las been ex- 
perimentally demonstrated to cause ionic conductivity and consequently instabilities in metal-oxide semiconductor (MOS) devices (2-5). The presence of sodium and other alkali species in thermally grown oxide films used for semiconductor device preparation has been extensively investigated $(6-8)$. Sources of alkali contamination have also been investigated in processing materials (9-13), in oxidation furnace refractories (14), and in evaporated gate metal films (15). Addition of about $5 \%$ chlorine or hydrogenchloride to the oxidation atmosphere has been reported to enhance the electrical stability of $\mathrm{Si}-\mathrm{SiO}_{2}$ structures, both through cleaning and passivating effects $(16-22)$. $\mathrm{HCl}$ diluted in an inert gas carrier (concentration up to $10 \%$ ) is used for periods of several hours immediately before oxidations to produce low mobile-ion content thermal oxide films for MOS device fabrication.

In a recent paper (23) the development of sodium contamination in oxidation atmospheres contained in transparent fused silica tubes operated at $1000^{\circ} \mathrm{C}$ was analyzed thermodynamically in terms of the impurity content primarily included in fused silica bulk resulting from the tube manufacturing process. Transparent fused silica tubes currently used in most semiconductor processing furnaces contain about $10 \mathrm{ppm}$ sodium (24-25). In situ cleaning of fused silica tubes at $1300^{\circ} \mathrm{K}$ results in removal of material from the inner tube wall surface creating a sodium-depleted layer. This in turn reduces the sodium content in the oxidation ambient, allowing the thermal growth of cleaner oxide films on silicon wafers. However, due to its high diffusivity in $\mathrm{SiO}_{2}\left[D=2 \times 10^{-6} \mathrm{~cm}^{2} / \mathrm{sec}\right.$ at $1000 . \mathrm{C}$ (26)] sodium from furnace refractories or from the room atmosphere around the oxidation tube may be incorporated into the fused silica wall contributing to the maintenance of its contamination level. When fused silica oxidation tubes are replaced by silicon tubes, the conditions established in the oxidation ambient are expected to be more favorable for growing clean thermal oxide films on silicon wafers. This is caused by the low sodium content in silicon tubes fabricated by chemical vapor deposition through hydrogen reduction of trichlorosilane. This process produces high purity polysilicon with only 10 $\mathrm{ppb}$ sodium contamination, 1000 times less sodium content than in fused silica tubes $(28)$. However, due to external contamination sources (i.e., sodium from refractories and room ambient), periodic in situ cleaning of the tube is necessary to maintain appropriate conditions in the oxidation atmosphere. The cleaning interval for both fused silica or silicon tubes is determined by the boundary conditions at the tube wall outer surface and the dilfusion of sodium in the tube wall. The diffusion coefficient of sodium in polycrystalline silicon is higher than in single crystal silicon due to grain boundary effects. At $1000^{\circ} \mathrm{C}$ the latter is $D=3 \times 10^{-6} \mathrm{~cm}^{2} / \mathrm{sec}(26)$. Similar effects were reported on the diffusion of boron in silicon at $1050^{\circ} \mathrm{C}$ (27).

The work presented here is an extension of the previous analysis on the behavior of fused silica oxidation tubes at $1000^{\circ} \mathrm{C}(23) .1$ Silicon oxidation tube behavior resembles the fused silica tube behavior except for the initial low sodium content when the tube is new. The effects of $\mathrm{HCl}$ cleaning on these tubes are also analyzed.

\section{Oxidation of Silicon Wafers in Silicon Oxidation Tubes}

The kinetics of silicon oxidation have been extensively studied by different authors for a number of temperatures in the range of $800^{\circ}-1200^{\circ} \mathrm{C}$ and for several oxidation atmosphere compositions contained in fused silica tubes [most early work on this subject is listed in bibliographic compilations on MOS technology $(9,30)]$. It was shown that the addition of trace amounts of water to the oxidation ambient causes a significant increase of silicon oxidation rate for all silicon orientations (31). It has also been shown that the equilibrium sodium density in oxidation atmospheres at $1300^{\circ} \mathrm{K}$ significantly increases when a few ppm water are added to the oxidation atmosphere (23). From these results it can be stated that the preparation of clean, low mobile ion content oxide films on silicon wafers is controlled primarily by four parameters: the oxidation temperature, the amount of sodium (in general, alkali) contamination in the tube wall bulk, the amount of water content in the oxidation atmosphere, and the furnace environment. The use of strictly controlled hydrocarbon-free dry oxy'gen in addition to alkali-free oxidation tubes operated at high temperatures (above $1000^{\circ} \mathrm{C}$ ) may result in clean thermal oxide preparations if appropriate care is taken concerning clean room environments around oxidation facilities. For high temperature (close to $1200^{\circ} \mathrm{C}$ ) processes where devitrification of fused sılica may produce serious problems, silicon tubes are preferred due to their better mechanical behavior and low sodium contamination level.

In the present work, the equilibrium atmosphere established at $1300^{\circ} \mathrm{K}$ in a silicon oxidation tube was studied theoretically for a number of cases of practical interest. ${ }^{2}$ Table I shows the equilibrium atmo-

1 For these thermodynamlc calculations data at $1300^{\circ} \mathrm{K}$ are used. The scheme for these calculations is outlined in the appendix of Ref. 23. Because of errors and approximations involved in ther. modynamic data used to evaluate the equllibrium results, an ab. relatuve error is nuch smaller.

Toble I. Equilibrium otmosphere in silicon wet oxidotion tube ol $1300^{\circ} \mathrm{K}$

Sodjum content in sillcon bulk: $10 \mathrm{ppb}$, oxygen at $1 \mathrm{~atm}$, water at $10^{-4}$ atm

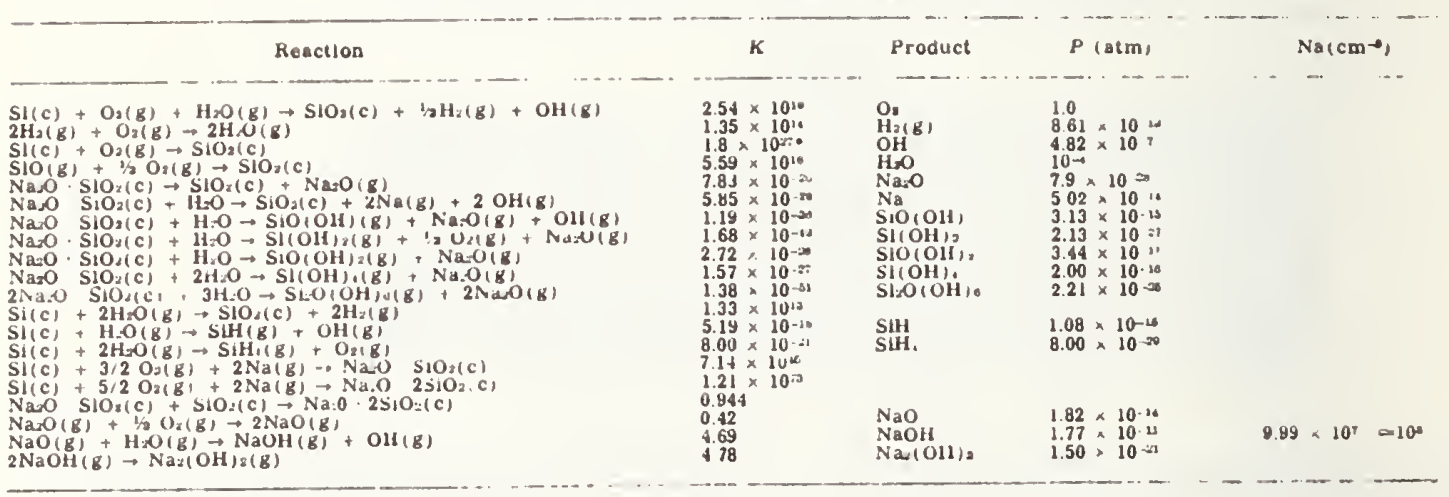

- Rapld formation of a sllica film on the sillcon tube. 
sphere resulting in a typical silicon oxidation tube operated at $1300^{\circ} \mathrm{K}$ using pure oxygen at 1 atm plus $100 \mathrm{ppm}$ water. Sodium in the tube wall might be assumed to be sodium metasilicate $\left[\mathrm{Na}_{2} \mathrm{O} \cdot \mathrm{SiO}_{2}(\mathrm{c})\right]$ and sodium silicate $\left[\mathrm{Na}_{2} \mathrm{O} \cdot 2 \mathrm{SiO}_{2}(\mathrm{c})\right]$. Measurements of sodium vaporization from silica glasses (32) indicate that sodium metasilicate might be dominant; deviations of the value $\mathrm{HH}^{\circ}{ }^{\circ} 298=-376.8 \mathrm{kcal} / \mathrm{mole}$ calculated for $\mathrm{Na}_{2} \mathrm{O} \cdot \mathrm{SiO}_{2}$ (c) from the JANAF value (33) is ascribed to solution effects of $\mathrm{Na}_{2} \mathrm{O} \cdot x \mathrm{SiO}_{2}$ species. Silicon and water react to form $\mathrm{SiO}_{2}$ (c) (equilibrium reaction constant $K=1.33 \times 10^{13}$ ). Sodium metasilicate is incorporated in the oxide film developed on the tube wall and evaporates to build up in the oxidation chamber an atmosphere containing about $10^{8}$ sodium atoms $/ \mathrm{cm}^{3}$, including both atomic and molecular species; $\mathrm{NaOH}$ is the most abundant compound. If no water is present in the oxidation ambient, the sodium content is negligible $\left[\mathrm{P}\left(\mathrm{Na}_{2} \mathrm{O}\right)=7.9 \times 10^{-23} \mathrm{~atm}\right]$. This condition prevails as long as the sodium level in silicon bulk is only $10 \mathrm{ppb}$.

\section{Oxidation Tube Cleaning}

Periodic in situ cleaning at oxidation temperature is required to keep silicon oxidation tubes clean under operative conditions. Dilute hydrogen chloride is generally used for rather long periods in the oxidation chamber to assure proper cleaning of the wall. Assuming $100 \mathrm{ppm}$ water $\left(10^{-4} \mathrm{~atm}\right)$ in addition to $10 \%$ $\mathrm{HCl}$ in a silicon tube operated at $1300^{\circ} \mathrm{K}$, the relevant reactions occurring are shown in Table II. Sodium chloride is formed from the interaction with sodium glasses contained in the silica film formed on the silicon tube wall. At equilibrium, the sodium number density in the atmosphere is $3.66 \times 10^{15}$ atoms $/ \mathrm{cm}^{3}$. This is $10^{7}$ times larger than the equilibrium sodium density normally present in the oxidation ambient. It should be emphasized that these results refer to equilibrium conditions. Although most reactions proceed rapidly at the inner tube wall surface, diffusion effects in the bulk may limit to some extent the applicability of this analysis. However, the enhanced sodium diffu- sion in polysilicon will reduce this limitation. The density of the resulting species at the surface could be lower, thus reducing the amount of sodium (or other species) actually removed. No attempts are made here to explore the kinetics of these reactions although it can be seen that hydrogen chloride cleaning is predicted to be very effective in agreement with current empirical observation.

The use of dry chlorine as a cleaning agent of silicon tubes should be avoided because of the risk involved due to its high reactivity with silicon. Table III shows that the tube could be severely damaged by chlorine if the protective silica film deposited on the inner tube wall has pinholes through which chlorine may come in contact with silicon to produce quantities of $\mathrm{SiCl}_{4}(\mathrm{~g}), \mathrm{SiCl}_{3}(\mathrm{~g})$, and $\mathrm{SiCl}_{2}(\mathrm{~g})$. However, if water is present in the system, hydrogen chloride is generated, moderating the aggressive behavior of dry chlorine.

\section{Oxidotion Tube Conditioning}

The silica film formed on the tube wall can be removed by hydrogen at oxidation temperature. The formation of ivater generated through the hydirogen silica interaction contributes to the leaching of sodium flom the tube bulk. Table IV shows the relevant reactions taking place in the tube when $100 \mathrm{ppm}$ water $\left(10^{\cdots} \mathrm{atm}\right)$ is present in the hydrogen atmosphere. Sodium compounds such as $\mathrm{NaO}, \mathrm{Na} 2 \mathrm{O}, \mathrm{NaOH}$, and $\mathrm{Na}_{2}(\mathrm{OH})_{2}$ are formed in addition to atomic sodium. The total sodium equilibrium pressure in the tube atmosphere is $1.82 \times 10^{-8} \mathrm{~atm}$ resulting in a number density of $1.03 \times 10^{11}$ atoms $/ \mathrm{cm}^{3}$ where the atomic species is the most abundant one due to the reducing action of hydrogen. Although the use of hydrogen around an oxidation facility involves risks and difficulties which may make it impractical, it is of value to observe that the use of diluted (less than $4 \%$ ) hydrogen in an inert gas carrier could make this procedure feasible by eliminating the risk of forming an explosive air-hydrogen mixture. If such an atmosphere is maintained in silicon oxidation tubes when they are

Table If. Equilibrium atmosphere in silicon oxidation tube cleaned with hydrogen chloride of $1300^{\circ} \mathrm{K}$

Sodium content In silicon bulk: $10 \mathrm{ppb}$, hydrogen chloride at $0.1 \mathrm{~atm}$, water at $10^{-\mathrm{a}} \mathrm{atm}$

\begin{tabular}{|c|c|c|c|c|}
\hline Reaction & $K$ & Product & $P(\operatorname{atm})$ & $\mathrm{Na}\left(\mathrm{cm}^{-3}\right)$ \\
\hline 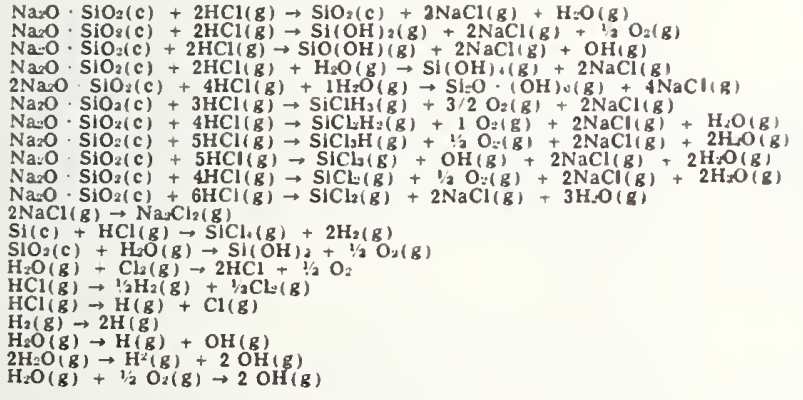 & 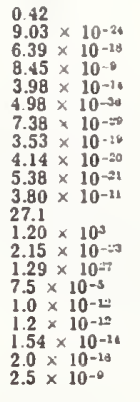 & 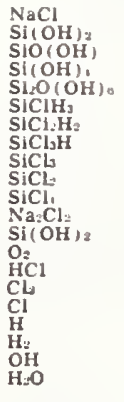 & $\begin{array}{l}6.48 \times 10^{-1} \\
1.66 \times 10^{-89} \\
8.45 \times 10^{-11} \\
2.01 \times 10^{-12} \\
2.26 \times 10^{-11} \\
5.50 \times 10^{-11} \\
1.05 \times 10^{-12} \\
6.51 \times 10^{-9} \\
5.48 \times 10^{-6} \\
9.91 \times 10^{-10} \\
9.04 \times 10^{-7} \\
1.14 \times 10^{-3} \\
1.67 \times 10^{-13} \\
1.67 \times 10^{-13} \\
0.1 \\
9.19 \times 10^{-9} \\
1.17 \times 10^{-6} \\
8.57 \times 10^{-8} \\
6.12 \times 10^{-3} \\
1.80 \times 10^{-11} \\
10^{-4} \times 1\end{array}$ & $6.43 \times 10^{1.3}$ \\
\hline
\end{tabular}

Toble III. Reaction constants fesulting in silicon oxidation tubes cleoned with chlorine at $1300^{\circ} \mathrm{K}$

Sodlum content in sillcon bulk: $10 \mathrm{ppb}$, chlorine at $0.1 \mathrm{~atm}$

\begin{tabular}{|c|c|c|c|}
\hline Reaction & $\boldsymbol{K}$ & Product & $P$ (atm) \\
\hline 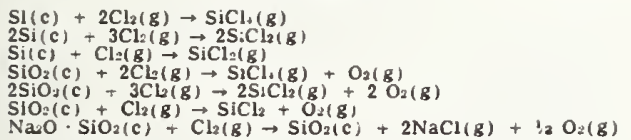 & $\begin{array}{l}3.77 \times 10^{-16} \\
4.74 \times 10^{-9} \\
3.50 \times 10^{8} \\
2.11 \times 10^{-5} \\
1.46 \times 10^{-23} \\
1.96 \times 10^{-20} \\
8.43\end{array}$ & $\begin{array}{l}\mathrm{SiCl} \\
\mathrm{SiCL} \\
\mathrm{SiCL}\end{array}$ & $\begin{array}{l}3.77 \times 10^{17 *} \\
6.91 \times 10^{12 . *} \\
3.50 \times 10^{7}\end{array}$ \\
\hline
\end{tabular}

- Rapld formation of these compounds. 
Table IV. Equilibrium atmosphere in silicon oxidation tube cleoned with wet hydrogen at $1300^{\circ} \mathrm{K}$

Sodium. cuntent In sllicon bulk. $10 \mathrm{ppb}$, hydrogen at $1 \mathrm{~atm}$, water at 10 atm

\section{Reaction}

$\mathrm{SiO}_{2}(\mathrm{c}), \mathrm{H}:(\mathrm{g})+\mathrm{H} . \mathrm{O}(\mathrm{g}) \rightarrow \mathrm{SiH}(\mathrm{g})+3 \mathrm{OHI}(\mathrm{g})$

$\mathrm{SjO}_{21}(\mathrm{C}+2 \mathrm{H}(\mathrm{g}) \overrightarrow{\mathrm{SiH}} \mathrm{ig}) \mathrm{O}$ )

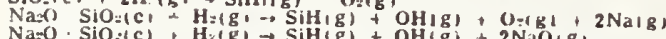

$\mathrm{Na}=$. SiO:(c) $\mathrm{H}\left(\mathrm{H}(\mathrm{g}) \rightarrow \mathrm{SiH}(\mathrm{g})+\mathrm{OH}_{(g)+2 \mathrm{NaO}(\mathrm{g})}\right.$

$\mathrm{Si}(\mathrm{c})+\mathrm{H}=\mathrm{O}(\mathrm{g}) i^{\rightarrow} \mathrm{SiO}=(\mathrm{C})+2 \mathrm{H},(\mathrm{g})$

$\left.2 \mathrm{NaOH}(\mathrm{g}) \rightarrow \mathrm{Na}_{-1} \mathrm{OH}\right) \cdot(\mathrm{g})$

Na:Uig) $\rightarrow$ Nallig) + Naig

$2 \mathrm{H}_{2} \mathrm{O} \rightarrow \mathrm{Ha}(\mathrm{gl}+2 \mathrm{OH}(\mathrm{g})$

$\mathrm{H}_{2} \mathrm{O}(\mathrm{g})+\mathrm{H} \mathrm{Oa}_{2}(\mathrm{~g}) \rightarrow 2 \mathrm{OH}(\mathrm{g})$

Table V. JANAf thermodynamic dala used to calculate equilibrium conditions ol $1300 \mathrm{~K}$ for reocuons listed in Tables $1.1 \mathrm{Y}$
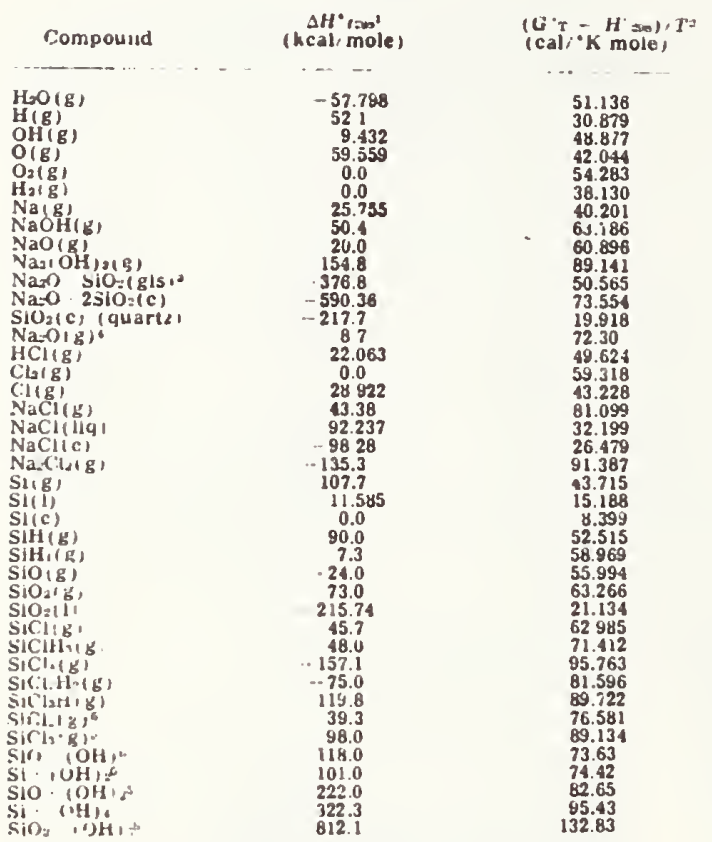

iH ... - standirf enthalpy ol cormation

if: if $\ldots T$. Ginlas energy fui-reinn in the standard siate $1300 \%$

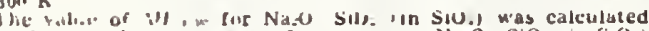

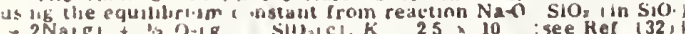

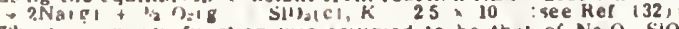

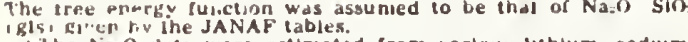

- Ihe va.o asta were estimated from varlous lithlum, sodium. and polascium oxides data given in the JANAF tables.

3 The hents of lormation were calculaled from bond energles as tained ty ullerpilation of the valucs given there.

liot r.ollin used for semiconductor proressing, the odum inipirity from the lube wall bulk and the silacin tilm on the tutw are ronstantly removed from the hor zone. The enhanced sodium diffusion in polyslicon intieast-s the sodium migiatıon into the silica tiins $x$ luch is being removed by the hydrogen reducing sction. Tlu, tube conditionung would reduce the need for per'ind." HCl cleanıng and consequently minimize the incliter.ce of other species (such as chlorine) in life widation chamber. Experimeutal evidence shows 1 1 . h'une is imerporated into oxide films thermally "rus a on sllcon wafers processed in oxidation tubes niculuily cleancd with $\mathrm{HCl}$ (34). This has proved to .re detrime:ntal for radiation-hard devices resulting in elc:tricai ustabilities (35).

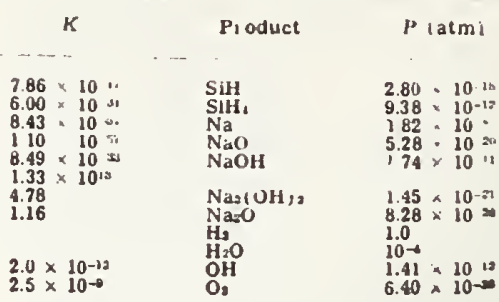

\section{Conclusions}

The above results show that the dominant factor in the preparation of clean thermal uxides is the pursty of the oxidation tube wall if ather process steps are kept under strict control. Such processes involve the wafer cleaning and handling prior to oxidation and metallization immediately after oxidation. When recently installed, new silicon tubes have a low sodium content and thus constitute an excellent material to enclose the oxidation atmosphere. 'This is due to the tube fabrication process (chemical vapor deposition: employing highly purified (low alkali) materials (28) Preparation of clean low movile un rontent thermal oxide films by wet oxidation of silicon wafers is in principle pussible if silicuil oxidation tubes are used. provided that the tube environment is clean enough to avoid inclusion of ambent contamination in the tube However, a silicon oxidation tube will tend lo develop alkalı contamination during normal operation unless special care is taken to isolate it froni external contamination. These ronditions are hard to maintain even in clean production-oriented facilities su periodic in stlu tube clearing is required. At oxidation temperatures sodium deposited on the exterior of the tube diffuses through the wall into the oxidation atmosphele contaminating the thermal oxide films growll un silicon wafers The rontamination proress may be originated by the fun nace refractories inspurity, the room ambient, and other factors external lo the tube The main advantage of employing silicon oxidativi tubes lies in the possibility of using temperatures higher than tolerated by fused silica tubes.

\section{Acknowledgment}

The uslliors ate very much indebted in Drs. W. Murray Bullis and kelneth F Gallıway of the ElecIronse "I'echnolugy IJvision tor tonstant stimulus during tliss work and riflical rewew of the manusiript

"llus work was coliduricd as part of the Semicon. ductor Techuology Program at the Nationa: Bureau of Standasds and was supported by the Defense Nu:lear Agency.

Maıuscript subrnitted Junt $17 \quad 1977$ sev!seo manisscript recelved Sept $8,1977$.

Any discussion of this papre will apiecal in d Discus. swon Section to be published in the Deremler 1978 Jounnal. All discussions for tlie Deténtial 1978 Discus. sion Section should be submitted hy Aug 1. 1978

Publiration custs of this article ivere assisied by the National Burean of Standards.

\section{HEFERENCES}

1. B E. Deal, This , lourual 121, 198C 1974)

2. T W llickmott, $J$ Appl l'hys . 46 2583, $1\{.75$,

3. C M Osburn and S I Raider. Thas Inirifl, 120. $136 ! 4(1973)$

4. T $H$ DiStefano and $J$ E Lewis, I lax. Sor Technol., 11, 1020 (1974)

5. G $\mathrm{f}$ Derbenwick, J. Appl Phys.. 48, 1127 (197i)

6. K G. Aubuchon, IEEE Trans. Nucl Scı., NS-18, No 6,117 (1971). 
7. E. H. Snow, A. S. Grove, B. E. Deal, and C. T. Sah, J. Appl. Phys., 36, 1664 (1965).

8. B. E. Deal, NBS Special Publication 337, Silicon Device Processing, C. P. Marsden, Editor, pp. 36-50, Washington, D.C. (1970)

9. S. I. Raider, L. V. Gregor, and R. Flitsch, This Journal, 120, 425 (1973).

10. B. Yurash and B. E. Deal, ibid., 115, 1191 (1968)

11. J. E. Barry, H. M. Donega, and T. E. Burgess, ibid. 116, 257 (1969).

12. W. R. Knolle, ibid., 120, 987 (1973).

13. W. R. Knolle and T. F. Retajczyk, Jr., ibid., 120, 1106 (1973).

14. D. R. Fewer and W. L. Gill, Technical Report No. RADC-TR-66-345, pp. 33-46 (1966); also available as NTIS Document AD-489-969.

15. K. G. Aubuchon, Hughes Research Laboratories Final Tech. Rep., contract N00014-71-C-0079 (1971).

16. R. J. Kriegler, Appl. Phys. Lett., 20, 449 (1972).

17. R. J. Kriegler, Y. C. Cheng, and D. R. Colton, This Journal, 119, 388 (1972)

18. R. J. Kriegler, Thin Solid Films, 13, 11 (1972).

19. R. J. Kriegler, in "Semiconductor Silicon 1973," H. R. Huff and R. R. Burgess, Editors, p. 363, The Electrochemical Society Softbound Symposium Series, Princeton, N.J. (1973)

20. R. J. Kriegler, in "12th Annual Proceedings Reliability Physics 1974," IEEE Catalog No. 74CHO839-1PHY (1974)

21. A. Rohatgi, S. R. Butler, and F. J. Feigl, Appl. Phys. Lett., 30, 104 (1977).

22. Y. J. van der Meulen, C. M. Osburn, and J. F. Ziegler, This Journal, 122, 284 (1975)

23. S. Mayo and W. H. Evans, ibid., 124, 780 (1977).
24. G. Hetherington, G. W. Stephenson, and J. A. Winterburn, Electronic Engint, 41, No. 495, 52 (1969); ibid. 41, No. 496, 44 (1969).

25. A. E. Owen and R. W. Douglas, J. Soc. Glass Technol., 43, 159T (1969).

26. H. F. Wolf, "Silicon Semiconductor Data" pp. 136 137, 526-527 Pergamon Press, Oxford (1969).

27. S. Horiuchi and R. Blanchard, Solid-State Electron., SC-18, 529 (1975).

28. W. Dietze, L. P. Hunt, and D. H. Sawyer, This Journal, 121, 1112 (1974).

29. E. S. Schlegel, IEEE Trans. Electron Devices, ed-14, 728 (1967); ibid., ed-15, 951 (1968).

30. A. H. Agajanian, 1BM Tech. Rep., 22, 1559 (1972).

31. E. A. Irene, This Journal, 121, 1613 (1974); E. A. Irene and Y. J. van der Meulen, ibid., 123, 1380 (1976).

32. G. L. Vidale, "Measurements of the Absorption of Resonance Lines III, Vaporization of Sodium from Sodium Silicate Glasses," Generall Electric Co., Technical Information Series, R60SD390 (1960).

33. JANAF Thermochemical Tables, D. R. Stull and H. Prophet, Editors, Second ed., NSRDS-NBS 37 (1971).

34. N. J. Chou, C. M. Osburn, and Y. J. van der Meulen, Appl. Phys. Lett., 22, 380 (1973).

35. R. A. Bunghard, B. L. Gregory, C. W. Gwyn, and G. F. Derbenwick, "Process Dependence of Radiation Effects in CMOS Integrated Circuits," Final Report, AFWL Contract 75-198 (1975).

36. O. H. Krikorian, in "Proceedings of the Symposium on Engineering with Nuclear Explosives," Conf. 700101, Vol. l, p. 481, Las Vegas, Nevada (1970). 

Director

Armed Forces Radiobiology Research Institute Defense Nuclear Agency

National Naval Medical Center

Bethesda, MD 20014

ATTN Technical Library

Commander in Chief

U.S. European Command, JCS

APO New York 09128

ATTN ECJ6-PF

Defense Communication Engineer Center

1860 Wiehle Avenue

Reston, VA 22090

ATTN R410 James W. McLean

ATTN R320 C. W. Bergman

Director

Defense Communications Agency

Washington, DC 20305

ATTN 930 Monte I. Burgett, Jr.

Defense Documentation Center

Cameron Station

Alexandria, VA 22314

ATTN TC

Director

Defense Intelligence Agency

Washington, DC 20301

ATTN DS-4A2

Director

Defense Nuclear Agency

Washington, DC 20305

ATTN STVL

ATTN RAEV

ATTN DDST

ATTN TITL Tech Library

Commander

Field Command

Defense Nuclear Agency

Kirtland AFB, NM 87115

ATTN FCPR

Director

Interservice Nuclear Weapons School

Kirtland AFB, NM 87115

ATTN Document Control

Director

Joint Strat TGT Planning Staff JCS

Offutt AFB

Onaha, NE 68113

ATTN JLTW-2
Chief

Livermore Division Fld Command DNA

Lawrence Livermore Laboratory

P.0. Box 808

Livermore, CA 94550

ATTN FCPRL

Director

National Security Agency

Ft. George G. Meade, MD 20755

ATTN Orland 0. Van Gunten R-425

ATTN TDL.

$0 \mathrm{JCS} / \mathrm{J}-3$

The Pentagon

Washington, DC 20301

ATTN J-3 RDTA BR WWMCCS Plans Div

Under Secretary of Defense for Rsch \& Engrg

Department of Defense

Washington, DC 20301

ATTN S\&SS (OS)

Project Manager

Army Tactical Data Systems

U.S. Army Electronics Command

Fort Monmouth, NJ 07703

ATTN DRCPN-TDS-SD

ATTN Dwaine B. Huewe

Commander

BMD System Command

P.0. Box 1500

Huntsville, AL 35807

ATTN BDMSC-TEN

Commander

Frankford Arsenal

Bridge and Tacony Streets

Philadelphia, PA 19137

ATTN SARFA-FCD

Commander

Harry Diamond Laboratories

2800 Powder Mill Road

Adelphi, MD 20783

ATTN DRXDO-EM

ATTN DRXDO-NP

ATTN DRXDO-RB

ATTN DRXDO-TF

ATTN DRXDO-RCC

ATTN DRXDO-TI Tech Library

ATTN J. McGarrity

Commanding officer

Night Vision Laboratory

U.S. Army Electronics Command

Fort Belvoir, VA $\angle 2060$

ATTN Capt. Allan S. Parker 
Commander

Picatinny Arsenal

Dover, NJ 07801

ATTN SARPA-ND-C-E

ATTN SMUPA-ND-N-E

ATTN SMUPA-FR-S-P

ATTN SARPA-ND-N

ATTN SMUPA-ND-D-B

ATTN SMUPA-ND-W

ATTN SARPA-FR-E

\section{Commander}

Redstone Scientific Information Center U.S. Army Missile Command

Redstone Arsena 1, AL 35809

ATTN Chief, Documents

Secretary of the Army

Washington, DC 20310

ATTN ODUSA or Daniel Willard

Director

TRASANA

White Sands Missile Range, NM 88002 ATTN ATAA-EAC

\section{Director}

U.S. Army Ballistic Research Labs

Aberdeen Proving Ground, MD 21005

ATTN DRXBR-X

ATTN DRXBR-VL (2)

ATTN DRXBR-AM

ATTN DRXRD-BVL

\section{Chief}

U.S. Army Communications Sys. Agency

Fort Monmouth, NJ 07703

ATTN SCCM-AD-SV Library

\section{Commander}

U.S. Army Electronics Command

Fort Monmouth, NJ 07703

ATTN DRSEL-TL-IR

ATTN DRSEL-CE-T

ATTN DRSEL-CT-HDK

ATTN DRSEL-GG-TD

ATTN DRSEL-TL-MD

ATTN DRSEL-TL-ND

ATTN DRSEL-PL-ENV

Cominander

U.S. Army Electronics Proving Ground

Fort Huachuca, AZ 85613

ATTN STEEP-MT-M

Commandant

U.S. Army Engineer School

Fort Belvoir, VA 22060

ATTN ATSE-CTD-CS
Commander-in-Chief

U.S. Army Europe and Seventh Army

APO New York 09403 (Heidelberg) ATTN ODCSE-E AEAGE-PI

Commandant

U.S. Army Field Artillery School

Fort Sil1, OK 73503

ATTN ATSFA-CTD-ME

Commander

U.S. Army Mat \& Mechanics Rsch Center Watertown, MA 02172

ATTN DRXMR-HH

Commander

U.S. Army Materiel Dev. \& Readiness Cmd.

5001 Eisenhower Avenue

Alexandria, VA 22333

ATTN DRCDE-D

Commander

U.S. Army Missile Command

Redstone Arsenal, AL 35809

ATTN DRSI -RGP

ATTN DRCPM-PE-EA

ATTN DRSMI -RGP

ATTN DRSMI -TRA

Chief

U.S. Army Nuc. and Chemical Surety Group B1dg. 2073, North Area

Fort Belvoir, VA 22060

ATTN MOSG-ND

Commander

U.S. Army Nuclear Agency

7500 Backlick Road

Building 2073

Springfield, VA 22150 ATTN ATCN-W

Commander

U.S. Army Tank Automotive Command

Warren, MI 48090

ATTN DRCPM-GCM-SW

Commander

U.S. Army Test and Evaluation Command

Aberdeen Proving Ground, MD 21005 ATTN DRSTE-EL

ATTN DRSTE-NB

Commander

White Sands Missile Range

White Sands Missile Range, NM 88002 ATTN STEWS-TE-NT 
Chief of Naval Research

Navy Department

Arlington, VA 22217 ATTN 427

Commanding Officer

Naval Avionics Facility

21 st and Arlington Avenue

Indianapolis, IN 46218

ATTN 942

Commander

Naval Electronic Systems Command Naval Electronic Systems Cmd Has

Washington, DC 20360

ATTN 5045I1

ATTN 5032

ATTN PME 117-21

ATTN 50451

ATTN ELEX 05323

Commanding Officer

Naval Intelligence Support Center

4301 Suitland Road, B1dg. 5

Washington, DC 20390

ATTN NISC-45

Commander

Naval Ocean Systems Center

San Diego, CA 92152

ATTN H. F. Wong

Director

Naval Research Laboratory

Washington, DC 20375

ATTN 5210

ATTN 5216

ATTN 6631

ATTN 6440

ATTN 601 E. Wolicki

ATTN 4104

ATTN 7701

ATTN 2627

\section{Commander}

Nava? Sea Systems Command

Navy Department

Washington, DC 20362

A.TTN SEA-9931 (2)

Officer-in-Charge

Navay Surface Weapons Center

White Oak, Silver Spring, MD 20910

ATTN WA501 Navy NuC. Prgms Off.

ATTN WA50

ATTN WA52
Commander

Naval Surface Weapons Center

Dahigren Laboratory

Dahlgren, VA 22448

ATTN FUR Robert A. Amadori

Commander

Naval Weapons Center

China Lake, CA 93555

ATTN 533 Tech Library

Commanding Officer

Naval Weapons Evaluation Facility

Kirtland AFB

Albuquerque, NM 87117

ATTN ATG Mr. Stanley

Commanding Ofticer

Naval Weapons Support Center

Crane, IN 47522

ATTN 70242

ATTN 7024

Commanding Officer

Nuclear leapons Tng. Center Pacitic

Naval Air Station, North Island

San Diego, CA 92135

ATTN 50

Director

Strategic Systems Project Office

Navy Department

Washington, DC 20376

ATTN NSP-27331

ATTN NSP-2342

ATTN SP 2701

AF Aero-Propulsion Laboratory, AtSC

Wright-Patterson AFB, $\mathrm{OH} 45433$

ATTN POD P. E. Stover

AF Geophysics Laboratory, AFSC

Hanscom AFB, MA 01731

ATTN LQR Edward A. Burke

ATTN J. Emery Cormier

ATTN LGD-Stop 30 Freeman Shepherd

AF Institute of Technology, AU

Wright-Patterson AFB, $\mathrm{OH} 4.5433$

ATTN ENP Charles 3. Bridgman

AF Materials Laboratory, AFSC

Wright-Patterson AFB, OH 45433

ATTN LTE 
AF Weapons Laboratory, AFSC

Kirtland AFB, NM 87117

ATTN DEX

ATTN ELA

ATTN NTS

ATTN ELP Tree Section

ATTN NT Carl E. Baum

ATTN ELS

ATTN ELXT

AFTAC

Patrick AFB, FL 32925

ATTN TAE

ATTN TFS Maj. Marion F. Schneider

Air Force Avionics Laboratory, AFSC

Wright-Patterson AFB, OH 45433

ATTN AAT Mason Friar

ATTN DHM C. Friend

ATTN DH LtC. McKenzie

ATTN DHE H. J. Hennecke

Commander

ASD

Wright-Patterson AFB, OH 45433

ATTN ASD/ENESS

ATTN ASD-YH-EX

ATTN ENACC Robert L. Fish

Headquarters

Electronic Systems Division/YS

Hanscom AFB, MA 01731

ATTN YSEV

Headquarters

Electronic Systems Division/YW

Hanscom AFB, MA 01731

ATTN YWEI

\section{Commander}

Foreign Technology Division, AFSC

Wright-Patterson AFB, OH 45433

ATTN ETD/PDJC

ATTN ETDP

\section{Commander}

Ogden Air Logistics Center

Hi11 AFB, UT 84401

ATTN MMEWM

\section{Commander}

Rome Air Development Center, AFSC

Griffiss AFB, NY 13440

ATTN RBRAC

ATTN RBRP
Commander

Rome Air Development Center, AFSC Hanscom AFB, MA 01731

ATTN ETS

ATTN ET R. Buchanan

SAMSO/DY

P.0. Box 92960

Worldway Postal Center

Los Angeles, CA 90009

ATTN DYS

SAMSU/IN

P.0. Box 92960

Worldway Postal Center

Los Angeles, CA 90009

ATTN IND I. J. Judy

SAIISO/MN

Norton AFB, CA 92409

ATTN MNNH

SAMSO/RS

P.0. Box 92960

Worldway Postal Center

Los Angeles, CA 90009

ATTN RSSE

ATTN RSMG

SAMSO/SK

P.0. Box 92960

Worldway Postal Center

Los Angeles, CA 90009 ATTII SKF

SAMSO/SZ

P.0. Box 92960

Worldway Postal Center

Los Angeles, CA 90009

ATTN SZJ

Commander in Chief

Strategic Air Command

Offutt AFB, NB 68113

ATTN NRI-STINFO Library

ATTN XPFS

Department of Energy

Albuquerque Operations Office

P.0. Box 5400

Albuquerque, NM 87115

ATTN Document Control for WSSB 
University of California

Lawrence Livermore Laboratory

P.0. Box 808

Livermore CA 94550

ATTN Lawrence Cleland L-156

ATTN E. K. Miller L-156

ATTN Frederick R. Kovar L-31 (Class L-94)

ATTN Joseph E. Keller, Jr. L-125

ATTN Hans Kruger L-96 (Class L-94)

ATTN Tech. Info. Dept. $L-3$

ATTN Ronald L. Ott L-531

ATTN William J. Hogan L-389

ATTN Donald J. Meeker L-545 (Class L-153)

Los Alamos Scientific Laboratory

P.0. Box 1663

Los Alamos, NM 87545

ATTN DOC CON for J. Arthur Freed

ATTN DOC CON for Bruce $W$. Noel

Sandia Laboratories

P.0. Box 5800

Albuquerque, NM 87115

ATTN DOC CON for R. Gregory ORG 2140

ATTN DOC CON for 3141 Sandia Rpt Coll

ATTN DOC CON for J. A. Hood ORG 2110

Department of Commerce

National Bureau of Standards

Washington, DC 20234

ATTN Judson C. French

Aerojet Electro-Systems Co.

Div. of Aerojet-General Corporation

P.0. Box 296, 1100 W. Hollyvale Drive

Azusa, CA 91702

ATTN Thomas D. Hanscome

Aerospace Corporation

P.0. Box 92957

Los Angeles, CA 90009

ATTN John Ditre

ATTN Irving $M$. Garfunkel

ATTN S. P. Bower

ATTN Library

ATTN L. W. Aukerman

ATTN Julian Reinheimer

ATTN William W. Willis

Analog Technology Corporation

3410 East Foothill Boulevard

Pasadena, CA 91107

ATTN John Joseph Baum

AVCO Research \& Systems Group

201 Lowell Street

Wilmington, MA 01887

ATTN Research Lib. A830 Rm 7201
BDM Corporation, The

7915 Jones Branch Drive

McLean, VA 22101

ATTN T. H. Neighbors

BDM Corporation, The

P.0. Box 9274

Albuquerque International

Albuquerque, MM 87119

ATTN D. R. Alexander

Bendix Corporation, The

Communication Division

East Joppa Road

Baltimore, MD 21204

ATTN Document Control

Bendix Corporation, The

Research Laboratories Division

Bendix Center

Southfield, MI 48075

ATTN Mgr Prgm Dev Donald J. Niehaus

ATTN Max Frank

Boeing Company, The

P.0. Box 3707

Seattle, WA 98124

ATTN Howard W. Wicklein MS 17-11

ATTN Aerospace Library

ATTN Donald W. Egelkrout MS 2R-00

ATTN Itsu Amura

ATTN Robert S. Caldwell 2R-00

ATTN Carl Rosenberg 2R-00

Booz-Allen and Hamilton, Inc.

106 Apple Street

Tinton Falls, NJ 07724

ATTN Raymond J. Chrisner

California Institute of Technology

Jet Propulsion Laboratory

4800 Oak Grove Drive

Pasadena, CA 91103

ATTN J. Bryden

ATTN A. G. Stanley

Charles Stark Draper Laboratory, Inc.

555 Technology Square

Cambridge, MA 02139

ATTN Paul R. Kelly

ATTN Kenneth Fertig

Cincinnati Electronics Corporation

2630 Glendale-Milford Road

Cincinnati, $\mathrm{OH} 45241$

ATTN C. R. Stump

ATTN Lois Hammond 
Control Data Corporation

P.0. Box 0

Minneapolis, MN 55440

ATTN Jack Meehan

Cutler-Hammer, Inc.

AIL Division

Comack Road

Deer Park, NY 11729

ATTN Central Tech Files Anne Anthony

Denver, University of

Colorado Seminary

Denver Research Institute

P.0. Box 10127

Denver, CO 80210

ATTN Sec. Officer for Fred P. Venditti

Dikewood Industries, Inc.

1009 Bradbury Drive, S.E.

Albuquerque, NM 87106

ATTN L. Wayne Davis

E-Systems, Inc.

Greenville Division

P.0. Box 1056

Greenville, TX 75401

ATTN Library 8-50100

Effects Technology, Inc.

5383 Hollister Avenue

Santa Barbara, CA 93111

ATTN Edward John Steele

Exp \& Math Physics Consultants

P.0. Box 66331

Los Angeles, CA 90066

ATTN Thomas M. Jordan

Fairchild Camera and Instrument Corp

464 Ellis Street

Mountain View, CA 94040

ATTN Sec. Dept for 2-233 David K. Myers

Fairchild Industries, Inc.

Sherman Fairchild Technology Center

20301 Century Boulevard

Germantown, MD 20767

ATTN Mgr Config Data \& Standards

Florida, llniversity of

An Institution of Education

ATTN: Patricia B. Rambo

P.0. Box 284

Gainesville, FL 32601

ATTN D. P. Kennedy
Ford Aerospace \& Communications Corp.

3939 Fabian Way

Palo Alto, CA 94303

ATTN Edward R. Hahn MS-X22

ATTN Donald R. McMorrow MS G30

ATTN Samuel R. Crawford MS 531

Ford Aerospace \& Communications Operations

Ford \& Jamboree Roads

Newport Beach, CA 92663

ATTN Ken C. Attinger

ATTN E. R. Poncelet, Jr.

ATTN Tech Info Section

Franklin Institute, The

20th Street and Parkway

Philadelphia, PA 19103

ATTN Ramie H. Thompson

Garrett Corporation

P.0. Box 92248, 9851 Sepulveda Blvd.

Los Angeles, CA 90009

ATTN Robert E. Weir Dept 93-9

General Dynamics Corp.

Electronics Div. Orlando Operations

P.0. Box 2566

Orlando, FL 32802

ATTN D. W. Coleman

General Electric Company

Space Division

Valley Forge Space Center

Goddard Blvd, King of Prussia

P.0. Box 8555

Philadelphia, PA 19101

ATTN John L. Andrews

ATTN Joseph C. Peden VFSC. Rm 4230M

ATTN Larry I. Chasen

General Electric Company

Re-entry \& Environmental Systems Div

P.0. Box 7722

3198 Chestnut Street

Philadelphia, PA 19101

ATTN Robert $V$. Benedict

ATTN John W. Palchefsky, Jr.

General Electric Company

Ordnance Systems

100 Plastics Avenue

Pittsfield, MA 01201

ATTN Joseph J. Reidl 
General Electric Company

Tempo-Center for Advanced Studies

816 State Street (P.0. Drawer QQ)

Santa Barbara, CA 93102

ATTN William McNamera

ATTN M. Espig

ATTN Royden R. Rutherford

ATTN DASIAC

General Electric Company

Aircraft Engine Business Group

Evendale Plant Int Hwy $75 \mathrm{~S}$

Cincinnati, OH 45215

ATTN John A. Ellerhorst E 2

General Electric Company

Aerospace Electronics Systems

French Road

Utica, NY 13503

ATTN W. J. Patterson Drop 233

ATTN Charles M. Hewison Drop 624

General Electric Company

P.0. Box 5000

Binghamton, NY 13902

ATTN David W. Pepin Drop 160

General Electric Company-Tempo

ATTN: DASIAC

c/o Defense Nuclear Agency

Washington, DC 20305

ATTN William Alfonte

General Research Corporation

P.0. Box 3587

Santa Barbara, CA 93105

ATTN Robert D. Hill

Georgia Institute of Technology

Georgia Tech Research Institute

Atlanta, GA 30332

ATTN R. Curry (uncl only)

Grumman Aerospace Corporation

South Oyster Bay Road

Bethpage, NY 11714

ATTN Jerry Rogers Dept 533

GTE Sylvania, Inc.

Electronics Systems Grp-Eastern Div

77 A Street

Needham, MA 02194

ATTN James A. Waldon

ATTN Charles A. Thornhill Librarian

ATTN Leonard L. Blaisdell
GTE Sylvania, Inc.

189 B Street

Needhan Heights, MA 02194

ATTN H \& V Group

ATTN Paul B. Frederickson

ATTN Herbert A. U17man

ATTN Charles H. Ramsbottom

Gulton Industries, Inc.

Engineered Magnetics Division

13041 Cerise Avenue

Hawthorne, CA 90250

ATTN Engnmagnetics Div

Harris Corporation

Harris Semiconductor Division

P.0. Box 883

Melbourne, FL 32907

ATTN Carl F. Davis MS 17-220

ATTN Wayne E. Abare MS 16-111

ATTN T. L. Clark MS 4040

Hazeltine Corporation

Pulaski Road

Greenlawn, NY 11740

ATTN Tech Info Ctr M. Waite

Honeywell Incorporated

Avionics Division

2600 Ridgeway Parkway

Minneapolis, MN 55413

ATTN Ronald R. Johnson Al622

ATTN R. J. Kell MS S2572

Honeywel1 Incorporated

Avionics Division

13350 U.S. Highway 19 North

St. Petersburg, FL 33733

ATTN Harrison H. Noble MS 725-5A

ATTN Stacey H. Graff MS 725-5

Honeywe11 Incorporated

Radiation Center

2 Forbes Road

Lexington, MA 02173

ATTN Technical Library

Hughes Aircraft Company

Centinela and Teale

Culver City, CA 90230

ATTN John B. Singletary MS 6-D133

ATTN Dan Binder MS 6-D147

ATTN Kenneth R. Walker MS D157

ATTN Billy W. Campbel1 MS 6-E 170

Hughes Aircraft Company, El Segundo Sịte P.0. Box 92919

Los Angeles, CA 90009

ATTN Edward C. Smith MS A620

ATTN William W. Scott MS A1080 
IBM Corporation

Route $17 \mathrm{C}$

Owego, NY 13827

ATTN Harry W. Mathers Dept M41

ATTN Frank Frankovsky

IIT Research Institute

10 West 35th Street

Chicago, IL 60616

ATTN Irving N. Mindel

Int1. Tel \& \& Telegraph Corporation 500 Washington Avenue

Nutley, NJ 07110

ATTN Alexander T. Richardson

Ion Physics Corporation

South Bedford Street

Burlington, MA 01803

ATTN Robert D. Evans

IRT Corporation

P.0. Box 81087

San Diego, CA 92138

ATTN Leo D. Cotter

ATTN MDC

ATTN R. L. Mertz

JAYCOR

1401 Camino Del Mar

Del Mar, CA 92014

ATTN Eric P. Wenaas

JAYCOR

205 S. Whiting Street, Suite 500

Alexandria, VA 22304

ATTN Robert Sullivan

ATTN Catherine Turesko

Johns Hopkins University

Applied Physics Laboratory

Johns Hopkins Road

Laure 1, MD 20810

ATTN Peter E. Partridge

Kaman Sciences Corporation

P.0. Box 7463

Colorado Springs, CO 80933

ATTN Donald $H$. Bryce

ATTN Albert P. Bridges

ATTN John R. Hoffman

ATTN Jerry I. Lubell

ATTN W. Foster Rich

ATTN Walter E. Ware
Litton Systems, Inc.

Guidance \& Control Systems Division

5500 Canoga Avenue

Woodland Hills, CA 91364

ATTN Val J. Ashby MS 67

ATTN John P. Retzler

ATTN R. W. Maughmer

Litton Systems, Inc.

Electron Tube Division

1035 Westminster Drive

Williamsport, PA 17701

ATTN Frank J. McCarthy

Lockheed Missiles \& Space Co., Inc.

P.0. Box 504

Sunnyvale, CA 94088

ATTN Samuel I. Taimuty, Dept 85-85

ATTN L. Rossi, Dept 81-64

ATTN Benjamin T. Kimura, Dept.81-14

ATTN Edwin A. Smith, Dept 85-85

ATTN George F. Heath, Dept 81-14

Lockheed Missiles and Space Co., Inc.

3251 Hanover Street

Palo Alto, CA 94304

ATTN Tech Info Ctr D/Coll

M.I.T. Lincoln Laboratory

P.0. Box 73

Lexington, MA 02173

ATTN Leona Loughlin Librarian A-082

Martin Marietta Corporation

Orlando Division

P.0. Box 5837

Orlando, FL 32805

ATTN Mona C. Griffith Lib MP-30

ATTN William W. Mras MP-413

ATTN Jack M. Ashford MP-537

Martin Marietta Corporation

Denver Division

P.0. Box 179

Denver, CO 80201

ATTN Ben T. Graham MS P0-454

ATTN Research Lib 6617 Jay R. McKee

ATTN J. E. Goodwin Mail 0452

ATTN Paul G. Kase Mail 8203

McDonnell Douglas Corporation

P.0. Box 516

St. Louis, Missouri 63166

ATTN Tom Ender

ATTN Technical Library 


\author{
McDonnel1 Douglas Corporation \\ 5301 Bolsa Avenue \\ Huntington Beach, CA 92647 \\ ATTN Stanley Schneider \\ McDonnell Douglas Corporation \\ 3855 Lakewood Boulevard \\ Long Beach, CA 90846 \\ ATTN Technical Library, C1-290/36-84 \\ Mission Research Corporation \\ 735 State Street \\ Santa Barbara, CA 93101 \\ ATTN William C. Hart \\ Mission Research Corporation \\ P.0. Box 8693, Station C \\ A1buquerque, NM 87108
}

ATTN David E. Merewether

Mission Research Corporation - San Diego P.0. Box 1209

La Jolla, CA 92038

ATTN J. P. Raymond

ATTN V. A. J. Van Lint

Mitre Corporation, The

P.0. Box 208

Bedford, MA 01730

ATTN M. E. Fitzgerald

ATTN Library

National Academy of Sciences

ATTN: National Materials Advisory Board

2101 Constitution Avenue, NW

Washington, DC 20418

ATTN R. S. Shane Nat Materials Advsy

New Mexico, University of

Electrical Engineering \& Computer Science Dept

Albuquerque, NM 87131

ATTN Harold Southward

Northrop Corporation

Electronic Division

1 Research Park

Palos Verdes Peninsula, CA

90274

ATTN George H. Towner

ATTN: Boyce T. Ahlport

Northrop Corporation

Northrop Research and Technology Ctr

3401 West Broadway

Hawthorne, CA 90250

ATTN Orlie L. Curtis, Jr.

ATTN J. R. Srour

ATTN David N. Pocock
Northrop Corporation

Electronic Division

2301 West 120th Street

Hawthorne, CA 90250

ATTN Joseph D. Russo

ATTN John M. Reynolds

ATTN Vincent R. DeMartino

Palisades Inst for Research Services, Inc.

201 Varick Street

New York, NY 10014

ATTN Records Supervisor

Physics International Company

2700 Merced Street

San Leandro, CA 94577

ATTN Doc Con for Charles H. Stallings

ATTN Doc Con for John H. Huntington

$R$ \& D Associates

P.0. Box 9695

Marina Del Rey, CA 90291

ATTN S. Clay Rogers

Rand Corporation, The

1700 Main Street

Santa Monica, CA 90406

ATTN Cullen Crain

Raytheon Company

Hartwel1 Road

Bedford, MA 01730

ATTN Gajanan H. Joshi Radar Sys Lab

Raytheon Company

528 Boston Post Road

Sudbury, MA 01776

ATTN Harold L. Flescher

RCA Corporation

Government Systems Division

Astro Electronics

P.0. Box 800, Locust Corner

East Windsor Township

Princeton, NJ 08540

ATTN George J. Brucker

RCA Corporation

Camden Complex

Front \& Cooper Streets

Camden, NJ 08012

ATTN E. Van Keuren 13-5-2

Rensselaer Polytechnic Institute

P.0. Box 965

Troy, NJ 12181

ATTN Ronald J. Gutmann 
Research Triangle Institute

P.0. Box 12194

Research Triangle Park, NC 27709

ATTN Sec Officer for

ATTN Eng Div Mayrant Simons, Jr.

Rockwell International Corporation P.0. Box 3105

Anaheim, CA 92803

ATTN George C. Messenger FB61

ATTN Donald J. Stevens FA70

ATTN K. F. Hull

ATTN James E. Bell HATO

ATTN N. J. Rudie FA53

Rockwell International Corporation

5701 West Imperial Highway

Los Angeles, CA 90009

ATTN T. B. Yates

Rockwel1 International Corporation

Collins Divisions

400 Collins Road NE

Cedar Rapids, IA 52406

ATTN Mildred A. Blair

ATTN Dennis Sutherland

ATTN Alan A. Langenfeld

Sanders Associates, Inc.

95 Canal Street

Nashua, NH 03060

ATTN Moe L. Aitel NCA 1-3236

Science Applications, Inc.

P.0. Box 277

Berkeley, CA 94701

ATTN Frederick M. Tesche

Science Applications, Inc.

P.0. Box 2351

La Jolla, CA 92038

ATTN J. Robert Beyster

ATTN Larry Scott

Science Applications, Inc.

Huntsville Division

2109 W. Clinton Avenue

Suite 700

Huntsville, AL 35805

ATTN Noel R. Byrn

Science Applications, Inc.

P.0. Box 3507

Albuquerque, NM 87110

ATTN J. Roger Hill

Science Applications, Inc.

8400 Westpark Drive

McLean, VA 22101

ATTN William L. Chadsey
Singer Company (Data Systems), The

150 Totowa Road

Wayne, NJ 07470

ATTN Tech Info Center

Singer Company, The

ATTN: Security Manager

1150 McBride Avenue

Little Falls, NJ 07424

ATTN Irwin Goldman Eng Management

Sperry Flight Systems Division

Sperry Rand Corporation

P.0. Box 21111

Phoenix, AZ 85036

ATTN D. Andrew Schow

Sperry Rand Corporation

Sperry Division

Marcus Avenue

Great Neck, NY 11020

ATTN Charles L. Craig EV

ATTN Paul Maraffino

Sperry Univac

Univac Park, P.0. Box 3525

St. Pau1, MN 55165

ATTN James A. Inda MS 41T25

SRI International

333 Ravenswood Avenue

Mento Park, CA 94025

ATTN Philip J. Dolan

ATTN! Arthur Lee Whitson

SRI International

306 Wynn Drive, NW

Huntsville, AL 35805

ATTN MacPherson Morgan

Sundstrand Corporation

4751 Harrison Avenue

Rockford, IL 61101

ATTN Curtis B. White

Systron-Donner Corporation

1090 San Miguel Road

Concord, CA 94518

ATTN Gordon B. Dean

ATTN Harold D. Morris

Texas Instruments, Inc.

P.0. Box 5474

Dallas, TX 75222

ATTN Donald J. Manus MS 72

Texas Tech University

P.0. Box 5404 North College Station

Lubbock, TX 79417

ATTN Travis L. Simpson 
TRW Defense \& Space Sys Group One Space Park

Redondo Beach, CA 90278

ATTN 0. E. Adams R1-1144

ATTN H. H. Hol loway Rl-2036

ATTN Tech Info Center/S-1930

ATTN R. K. Plebuch RT-2078

ATTN Robert M. Webb R1-2410

TRW Defense \& Space Sys Group

San Bernardino Operations

P.0. Box 1310

San Bernardino, CA 92402

ATTN F. B. Fay

ATTN R. Kitter
United Technologies Corporation

Hamilton Standard Division

Bradley International Airport

Windsor Locks, CT 06069

ATTN Raymond G. Giguere

Vought Corporation

P.0. Box 5907

Dallas, TX 75222

ATTN Technical Data Ctr

Westinghouse Electric Corporation Defense and Electronic Systems Ctr P.0. Box 1693

Baltimore-Washington Intl Airport Baltimore, MD 21203

ATTN Henry P. Kalapaca MS 3525 
NBS-114A (REV. 7-73)

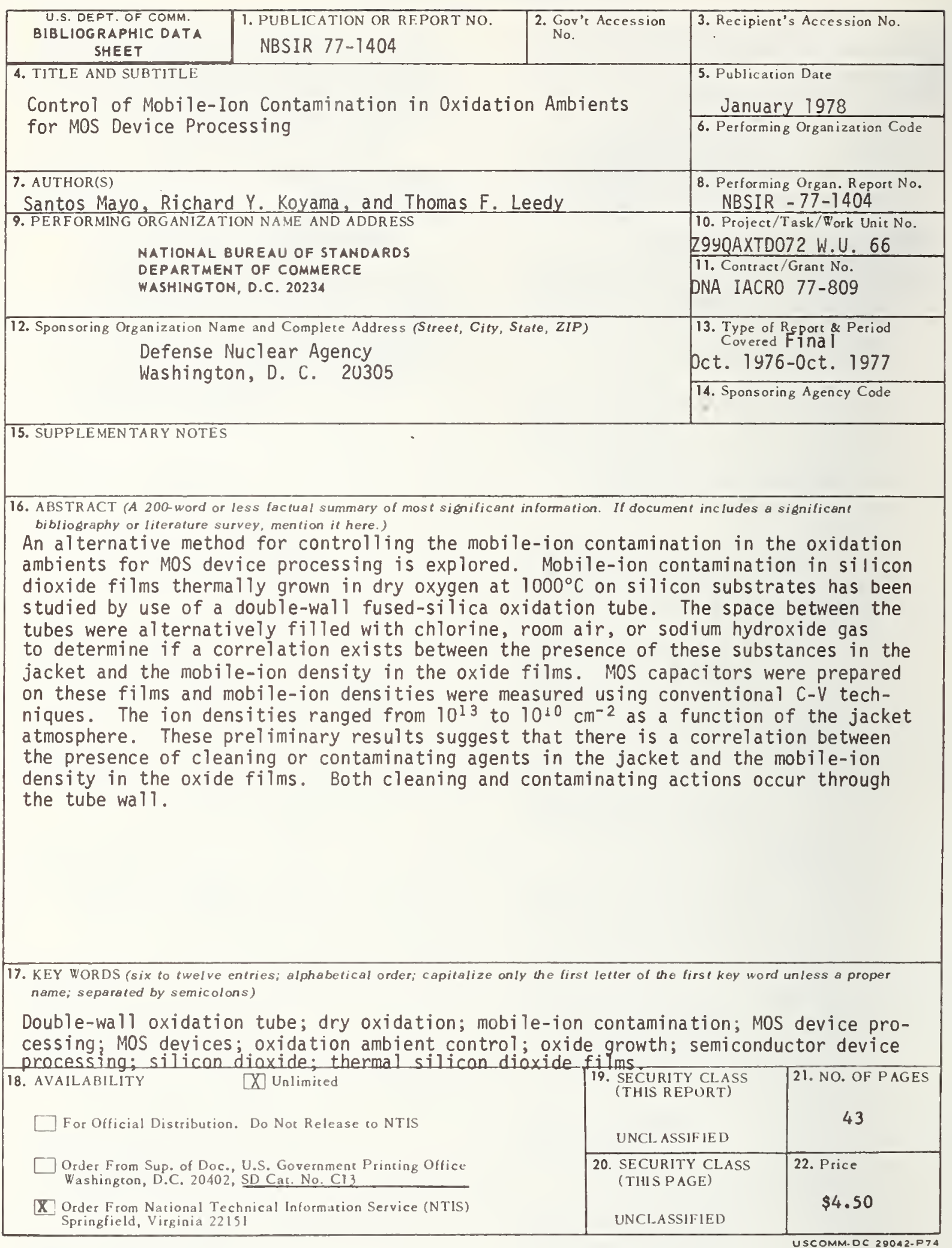

